\title{
Hygric properties of porous building materials (III): impact factors and data processing methods of the capillary absorption test
}

\author{
Chi Feng ${ }^{1,2^{*}}$, Hans Janssen ${ }^{1}$
}

1. KU Leuven, Department of Civil Engineering, Building Physics Section, 3001 Leuven, Belgium

2. China Academy of Building Research, 100013 Beijing, P.R. China

\begin{abstract}
The capillary absorption test is one of the most frequently performed material characterization tests. It provides the capillary absorption coefficient and the capillary moisture content, both are important material properties. Currently, full consensus concerning the experimental protocol and data processing of the capillary absorption test has not been reached yet. This paper studies the potential impact factors during the test and compares different methods for processing the raw data. Measurements on calcium silicate, ceramic brick, sintered glass and autoclaved aerated concrete are carried out, and published literature results are reviewed. The impact of sample size, sealing method, initial moisture content, temperature and personnel have been thoroughly analyzed, and proper recommendations are provided accordingly. Moreover, a new data processing model with a solid physical background for calculating the capillary absorption coefficient and the capillary moisture content has been proposed. It shows obvious advantages over other published models and is applicable for both ideal and irregular capillary absorption patterns.
\end{abstract}

Keywords: porous building material; capillary absorption test; capillary absorption coefficient; sorptivity; capillary moisture content

\section{Introduction}

Moisture is a crucial issue for the built environment. Moisture-related processes affect not only buildings' energy efficiency and service life [1-3] but also their indoor climate and air quality [4-6]. To have a correct understanding and a decent control of moisture-related processes, researchers and engineers all around the world have established numerous Heat-Air-Moisture (HAM) transfer models and developed many numerical tools for different applications [7-9].

Whatever the theoretical model or the numerical tool is, the hygric properties of porous building materials are indispensable input information. Currently, such properties are commonly determined through experiments [10-12], among which the capillary absorption test (also called the capillary uptake test, the free water uptake test, etc.) is one of the most frequently performed. It determines the capillary absorption coefficient $\left(A_{c a p}, \mathrm{~kg} \cdot \mathrm{m}^{-2} \mathrm{~s}^{-0.5}\right)$ and the capillary moisture content $\left(w_{c a p}, \mathrm{~kg} \cdot \mathrm{m}^{-3}\right)$. With additional non-destructive techniques (such as X-ray or NMR) for monitoring moisture content profiles within the sample, the moisture diffusivity (and permeability) can also be derived [13, 14]. Alternatively, the sorptivity $S\left(\mathrm{~m} \cdot \mathrm{s}^{-0.5}\right)$ can equally be derived from the capillary absorption test. As is shown in Eq.(1), $A_{c a p}$ and $S$ are related to each other via the water density $\left(\rho_{w}, \mathrm{~kg} \cdot \mathrm{m}^{-3}\right)$. Consequently, in this study we focus on $A_{\text {cap }}$ but the analysis and findings are similarly applicable to $S$. 
Postprint: Feng C, Janssen H. 2018. Hygric properties of porous building materials (III): impact factors and data processing methods of the capillary absorption test , Building and Environment, 134: 21-34.

doi: https://doi.org/10.1016/j.buildenv.2018.02.038

$$
A_{\text {cap }}=S \cdot \rho_{w}
$$

Unfortunately, despite the availability of many international and regional standards prescribing the procedures of the capillary absorption test [15-19], no broad consensus concerning the experimental protocol has been reached among different researchers, as the impact of many factors remains unclear. In general, these impact factors can be classified into three categories: the material sample factors, the environmental factors, and the operational factors. An example of a material sample factor is the sample size. The ISO 15148 [20] standard requires a minimal bottom surface area of 50 $\mathrm{cm}^{2}$ for each sample, whereas multiple researchers often use much smaller samples, with bottom surface areas ranging from 10 to $30 \mathrm{~cm}^{2}$ [11, 21-25]. It is not known if such small samples are sufficient or whether only larger samples can provide reliable experimental results. In addition, other examples representing environmental and operational factors include the recent controversy over the temperature's impact on $A_{\text {cap }}[21,23,25,26]$ as well as different opinions on whether self-adhesive films can be used for sealing the lateral sides of samples [11, 25, 27].

Besides potential impact factors for the experiment, an even more crucial aspect of the capillary absorption test also calls for a critical assessment - the data processing method. Different researchers often use diverse methodologies to process their raw data to $A_{c a p}$ and $w_{c a p}$, and their final results are subsequently not always directly comparable, especially when the capillary absorption process is not entirely regular. A recent example is the two papers [23, 25] - both published in this journal in 2016 - focusing on the impact of temperature on the capillary absorption test, wherein opposing opinions on this issue are brought forward. However, differences in the data processing methods can partially explain their different arguments: the authors of [25] adopted the one-tangent method (Section 4.2.1) whereas [23] employed the two-tangent method (Section 4.2.3). One more illustrative case in point is that the one-tangent method was used to calculate $A_{\text {cap }}$ of a specific aerated concrete in [12], leading to $0.036 \mathrm{~kg} \cdot \mathrm{m}^{-2} \mathrm{~s}^{-0.5}$, while with our data processing method proposed in this paper $0.043 \mathrm{~kg} \cdot \mathrm{m}^{-2} \mathrm{~s}^{-0.5}$ is obtained, roughly $20 \%$ higher.

This paper aims at providing in-depth analysis of the above-mentioned issues from a scientific researcher's perspective. For impact factors, we limit our discussion scope to some less studied and more controversial ones, namely sample size, sealing method, initial moisture content, temperature and personnel. When it comes to different data processing methods, we review the mainstream options for both regular and irregular capillary absorption patterns, and make a profound analysis of their respective pros and cons. A novel model with a solid physical background is finally proposed and validated.

\section{Materials and methods}

In this section, we will first introduce the material information and sample preparation for our measurements. Then the experimental setup and measurement procedure will be explained. It should be noted that our experimental protocol is based on our earlier experience [11, 25], primarily derived from the ISO 15148 [20] and the ASTM C1585 [28] standards. However, in our measurements some factors - such as the sample size and the initial moisture content - are not in full agreement with these standards, and we will discuss their impact specifically in Section 3.

\subsection{Material information and sample preparation}

To avoid disturbances by material evolution and (directional) heterogeneities, four homogeneous and stable materials - calcium silicate (CS), ceramic brick (CB), sintered glass (SG) and autoclaved aerated concrete $(\mathrm{AAC})$ - are chosen as target materials. Their bulk density $\left(\rho b u l k, \mathrm{~kg} \cdot \mathrm{m}^{-3}\right)$ and open 
Postprint: Feng C, Janssen H. 2018. Hygric properties of porous building materials (III): impact factors and data processing methods of the capillary absorption test , Building and Environment, 134: 21-34.

doi: https://doi.org/10.1016/j.buildenv.2018.02.038

porosity $(\phi)$ are obtained from the vacuum saturation test [29], while the vapor diffusion resistance factor $(\mu)$ and the equilibrium moisture content at RH $84.7 \%\left(u 84.7 \%, \mathrm{~kg} \cdot \mathrm{kg}^{-1}\right)$ are measured from the cup test [30] and the static gravimetric test [31], respectively. Mercury intrusion porosimetry (MIP) provides information on the pore structures, and the median pore-throat radius $\left(r_{50}, \mathrm{~m}\right)-$ which corresponds to the 50\% mercury saturation - is presented [32]. The capillary absorption test is performed for determining $A_{c a p}$ and $w_{c a p}$, with in-depth analysis in the rest of this paper. The average values from multiple samples of these properties are summarized in Table 1. In general, CS is strong in both hygroscopicity and capillarity, CB and SG are weak in hygroscopicity but strong in capillarity, and AAC is strong in hygroscopicity but weak in capillarity. Specifically for the research targets of this paper, $A_{\text {cap }}$ varies from $10^{-2}$ to $10^{0} \mathrm{~kg} \cdot \mathrm{m}^{-2} \mathrm{~s}^{-0.5}$ while $w_{\text {cap }}$ ranges from 200 to $800 \mathrm{~kg} \cdot \mathrm{m}^{-3}$. Due to these variations, these four materials can represent a broad spectrum of porous building materials with widely different hygric characteristics. It should be noted that SG is not a building material. However, because of its relatively large pores, gravity plays a noticeable impact on its capillary absorption process, showing a very typical irregular pattern. For this reason, we include it in this study.

Raw materials are cut into cubic samples with different bottom surface areas $\left(A, \mathrm{~m}^{2}\right)$ and heights $(H, \mathrm{~m})$. For each material and each size, 2-5 duplicate samples are selected. These samples are first measured by calipers reading $0.01 \mathrm{~mm}$ for precise size determination and then sealed at the lateral and top sides by either plastic films or epoxy. At the top surface, small holes are left for allowing air to escape. Moreover, when plastic sealing films are used, the bottom centimeter of the lateral sides is left uncovered, so that the film does not touch the water, which may disturb the measurement.

Table 1 Fundamental properties of target materials $\left(\mathbf{2 1 - 2 3}^{\circ} \mathrm{C}\right)$

\begin{tabular}{cccccccc}
\hline Material & $\rho_{\text {bulk }}\left(\mathrm{kg} \cdot \mathrm{m}^{-3}\right)$ & $\phi(\%)$ & $\mu^{\mathrm{a}}$ & $u_{84.7 \%}{ }^{\mathrm{b}}\left(\mathrm{kg} \cdot \mathrm{kg}^{-1}, \%\right)$ & $r_{50}(\mathrm{~m})$ & $A_{\text {cap }}\left(\mathrm{kg} \cdot \mathrm{m}^{-2} \mathrm{~s}^{-0.5}\right)^{\mathrm{c}}$ & $w_{\text {cap }}\left(\mathrm{kg} \cdot \mathrm{m}^{-3}\right)$ \\
\hline CS & 271 & 89.1 & 2.0 & 2.9 & $3.2 \times 10^{-7}$ & 1.01 & 756 \\
CB & 1818 & 32.6 & 11.6 & $<0.05^{\mathrm{d}}$ & $4.1 \times 10^{-6}$ & 0.61 & 210 \\
SG & 1414 & 36.5 & 5.8 & $<0.05^{\mathrm{d}}$ & $2.4 \times 10^{-5}$ & 3.75 & 272 \\
AAC & 462 & 81.4 & 7.4 & 3.1 & $-{ }^{\mathrm{d}}$ & 0.046 & 312 \\
\hline
\end{tabular}

${ }^{\mathrm{a}}$ Determined from dry cup test (RH $\left.11.3 \%-53.5 \%\right)$;

${ }^{\mathrm{b}}$ Adsorption from dry state;

${ }^{\mathrm{c}} \mathrm{Re}$-calculated for $20^{\circ} \mathrm{C}$ with Eq.(3);

${ }^{\mathrm{d}}$ Cannot be determined accurately.

\subsection{Experimental setup and measurement procedure}

The capillary absorption test can be performed either automatically or manually, both producing similar results [27]. In this study, we prefer the manual method for its simplicity in experimental setup and capability of multi-sample measurements.

The basic setup for our manual capillary absorption test is illustrated in Fig.1. During the capillary absorption process, samples stand on sample holders made of stainless steel with a negligible contact surface area. The sample holders are submerged 2-5 mm below the water level in a water container. In this study, deionized (not de-aired) water (with an electrical conductivity smaller than $20 \mu \mathrm{S} \cdot \mathrm{cm}^{-1}$ ) is used and the water level is maintained by regular re-filling.

Before starting the capillary absorption process, all sealed samples are dried at $70^{\circ} \mathrm{C}$ in a ventilated oven supplied with dry air for dry mass determination. Their dry mass without sealing is also determined beforehand, but only for bulk density calculation, not for capillary absorption data 
Postprint: Feng C, Janssen H. 2018. Hygric properties of porous building materials (III): impact factors and data processing methods of the capillary absorption test , Building and Environment, 134: 21-34.

doi: https://doi.org/10.1016/j.buildenv.2018.02.038

analysis. For mass determination within $1 \mathrm{~kg}$, a balance reading $0.001 \mathrm{~g}$ is used, and heavier samples are weighed on another balance reading $0.01 \mathrm{~g}$.

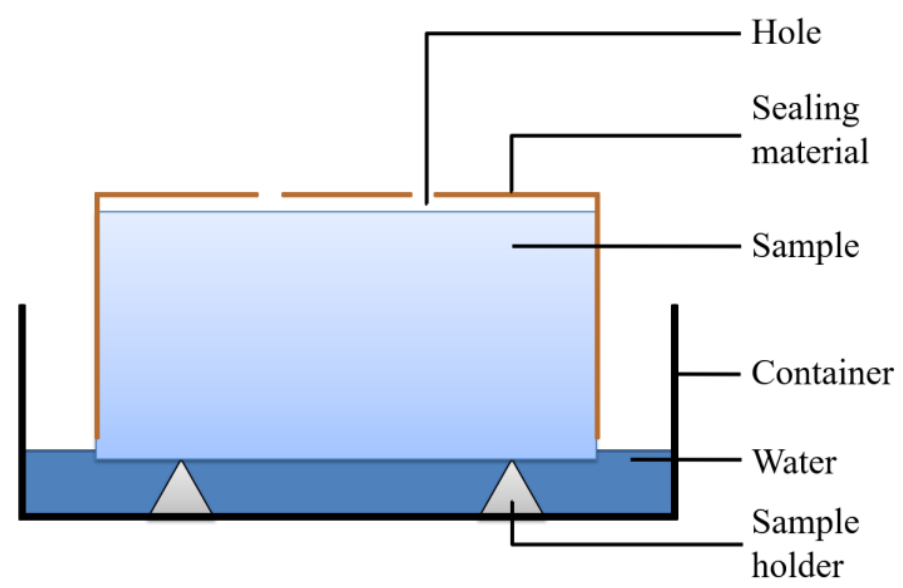

Fig.1 A manual experimental setup for the capillary absorption test

After cooling down to room temperature in a desiccator with desiccant $\left(\mathrm{CaCl}_{2}\right)$, oven-dried samples are put on the sample holders to start the capillary absorption. The moment the first sample touches water, the timer is started. From time to time samples are taken out of water, and the free water attached to the bottom is gently removed with a moist cloth. Then the samples are weighed and put back. We keep $20 \mathrm{~s}$ as the constant time for the "taking out - water removing - sample weighing - putting back" process. The (cumulative) time that the samples are not in contact with water is corrected for during the data processing (i.e. $20 \mathrm{~s}$ are deduced for the total absorption time for the $2^{\text {nd }}$ measurement, $40 \mathrm{~s}$ for the $3^{\text {rd }}, 60 \mathrm{~s}$ for the $4^{\text {th }} \ldots$ ).

Since temperature is a potential impact factor for the capillary absorption test, the water used in the test is also conditioned to room temperature in a closed container beforehand. During the test, evaporation causes a water temperature decrease of $2-3^{\circ} \mathrm{C}$. The water temperature in the container is monitored throughout the measurement, and an average value is ascribed.

\subsection{Methods for comparing the results}

Table 2 Repeatability and material errors (\%) of target materials

\begin{tabular}{ccccc}
\hline \multirow{2}{*}{ Material } & \multicolumn{2}{c}{$A_{\text {cap }}$} & \multicolumn{2}{c}{$w_{c a p}$} \\
& Repeatability error & Material error & Repeatability error & Material error \\
\hline CS & 1.6 & 0.4 & 1.6 & $-{ }^{\text {a }}$ \\
CB & 2.0 & 2.8 & 0.4 & 3.4 \\
SG & 6.3 & 4.3 & 5.7 & $-{ }^{\text {a }}$ \\
AAC & 8.2 & 7.1 & 1.6 & 3.8 \\
\hline${ }^{a}$ Cannot be determined accurately. & & &
\end{tabular}

For quantitative analysis of the experimental results, not only the widely used mean value and standard deviations but also the more delicate repeatability errors from measurements and material errors from inhomogeneity are employed, with detailed definitions and calculation methods explained in [11,33]. Table 2 summarizes the repeatability and material errors for our target materials regarding $A_{\text {cap }}$ and $w_{\text {cap }}$. The values for CS and AAC are cited from our earlier research [11], while the values for CB and SG are calculated based on our recent measurements. Differences are 
Postprint: Feng C, Janssen H. 2018. Hygric properties of porous building materials (III): impact factors and data processing methods of the capillary absorption test , Building and Environment, 134: 21-34.

doi: https://doi.org/10.1016/j.buildenv.2018.02.038

considered negligible, if they are smaller than or comparable with the repeatability and/or material errors. Paired T-tests [34] are also employed occasionally for evaluation.

\section{Impact factors}

In this section, we will discuss five factors - sample size, sealing method, initial moisture content, temperature and personnel - with possible impact on the capillary absorption test based on our own test outcomes as well as literature results. There is accumulating evidence and general consensus showing that time is very crucial for materials with noticeable hydration and/or carbonation processes [35-39], and that measurement direction has a significant impact on anisotropic materials [40-43], thus we don't analyze such factors in this study. Gravity will be analyzed profoundly in Section 4, so not included in this section, neither.

Note that all our $A_{\text {cap }}$ results in this section are derived based on the data processing methods recommended in Section 4, and have been normalized to values at $20^{\circ} \mathrm{C}$ based on Eq.(3) for a better comparison. For the $w_{c a p}$ calculations, the method recommended in Section 5 is adopted.

\subsection{Sample size}

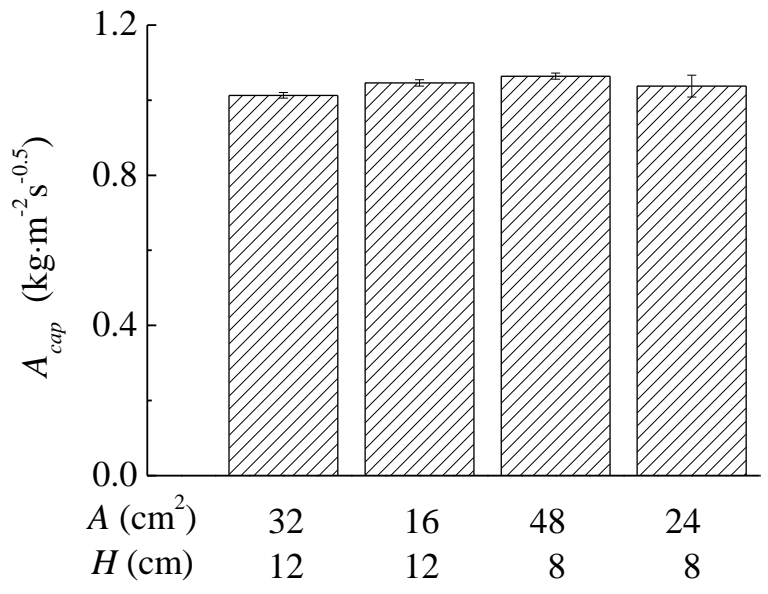

(a) $A_{\text {cap }}$ of CS

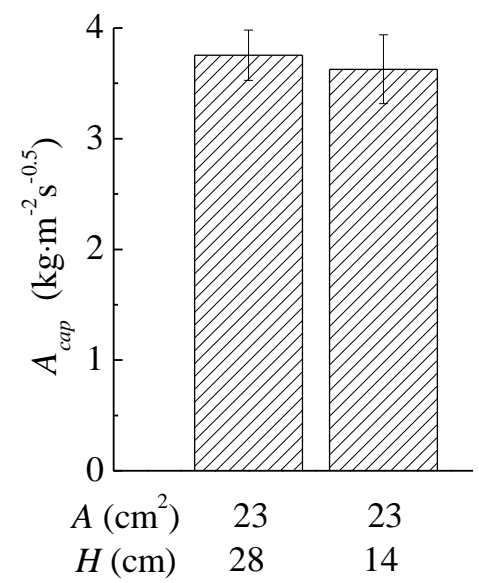

(c) $A_{\text {cap }}$ of SG

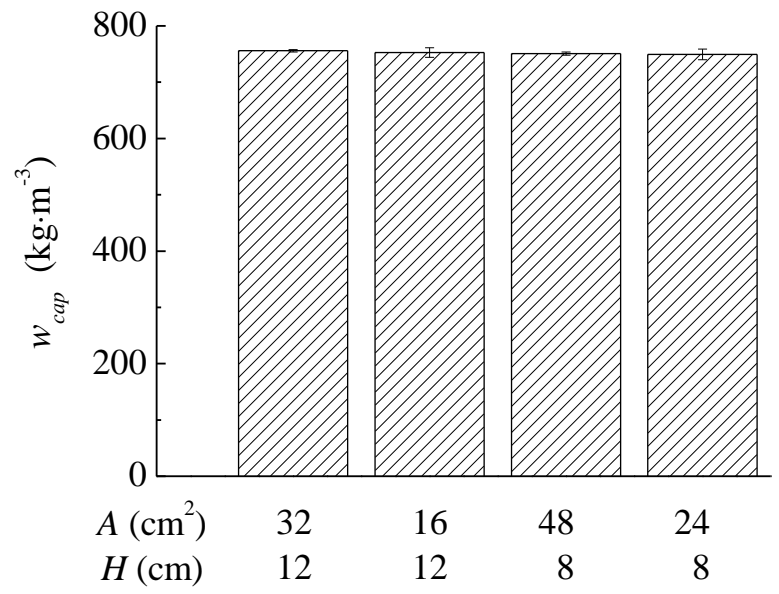

(b) $w_{\text {cap }}$ of CS

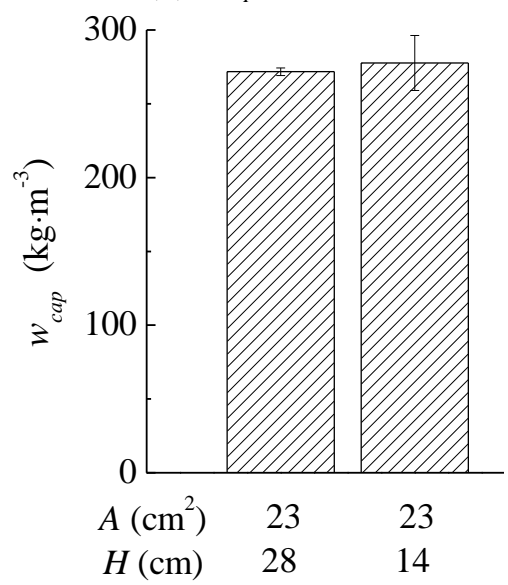

(d) $w_{\text {cap }}$ of SG

Fig.2 Experimental results of samples of different sizes

For the capillary absorption test, target materials are often cut into small samples. The ISO 15148 standard [20] requires the bottom surface area $A \geq 50 \mathrm{~cm}^{2}$ for each sample. In addition, if $A$ is smaller than $100 \mathrm{~cm}^{2}$, then at least 6 duplicate samples should be used, with a total $A$ no smaller than 300 $\mathrm{cm}^{2}$. Similarly, the ASTM C1585 standard [28] also regulates this aspect, suggesting cylindrical 
Postprint: Feng C, Janssen H. 2018. Hygric properties of porous building materials (III): impact factors and data processing methods of the capillary absorption test , Building and Environment, 134: 21-34.

doi: https://doi.org/10.1016/j.buildenv.2018.02.038

samples with a diameter no less than $10 \mathrm{~cm}$ should be used and at least 2 duplicate samples are necessary. It is easily understandable that $A$ should not be too small to ensure an acceptable accuracy [20]. But the limit may subject to discussion. A cubic of $10 \mathrm{~cm}$ side length or a cylinder of $10 \mathrm{~cm}$ in diameter is not so easy for handling by one hand, so a smaller size could improve handling convenience. Moreover, some materials can hardly be cut into the required size (such as bricks in the longitude direction). Besides the bottom surface area $A$, the height $H$ of the sample is also an important dimension, as it determines the duration of the test. However, it has received inadequate attention. The ISO 15148 standard [20] provides no requirement for it, while the ASTM C1585 standard [28] simply requires $5 \mathrm{~cm}$ or more (for concrete).

To investigate the possible impact of $A$ and $H$, we cut CS and SG into samples of different sizes to represent materials with ideal and irregular capillary absorption processes. Capillary absorption tests on these samples are performed under almost unchanged conditions. Results are illustrated in Fig.2 with error bars representing the standard deviations. It is clearly shown that for both $A_{\text {cap }}$ and $w_{c a p}$, no significant difference can be observed between samples of different sizes. In addition, it has been proved that even with small samples, the capillary absorption test is still highly repeatable [11, 28, 43], indicating the possibility to reduce $A$ without sacrificing experimentally reliability. Thus, it's clear that in many cases a bottom surface area of an individual sample in the order of $15-20 \mathrm{~cm}^{2}$ should suffice, if the material is not extremely inhomogeneous or doesn't contain very coarse particles with a size in $\mathrm{cm}$ or even larger. Besides handling convenience, the choice of $H$ depends largely on the $A_{c a p}$ of the material. It would be favorable to ensure an overall experimental duration of tens of minutes up to a couple of days.

\subsection{Sealing}

To reduce evaporation, the lateral and top sides of the sample are often sealed with non-permeable materials. In general, there are two sealing methods: either to cover these sides with a(n adhesive) film [11] or to coat them with paint or resin [22]. In the ASTM C1585 standard [28], it is clearly stated that both methods are acceptable. However, Bomberg et al [27] claimed that the self-adhesive tapes should not be used but without giving any experimental support or theoretical explanations. To clarify the impact of sealing methods, we perform capillary absorption tests on the same duplicate samples of all four materials studied in this paper with different sealing methods: a) with non-adhesive plastic film, b) with self-adhesive plastic film, and c) coated with epoxy (only on CB samples).

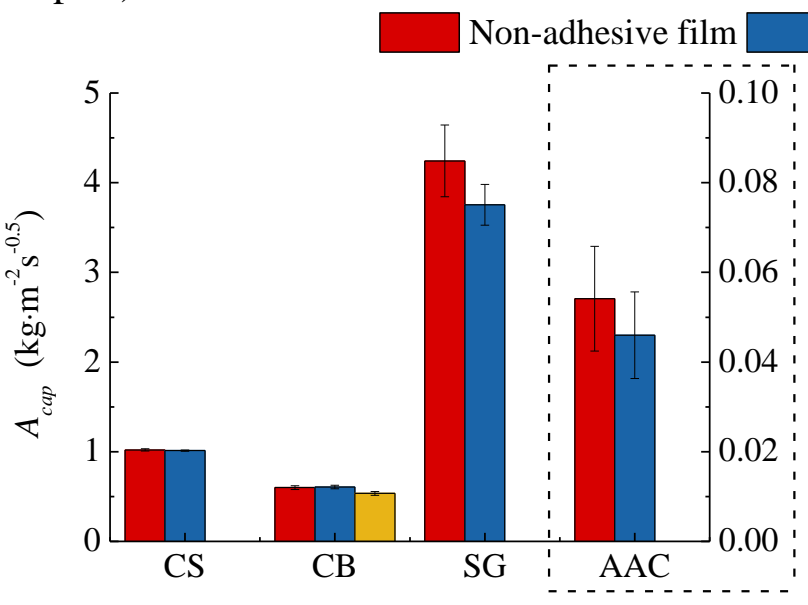

(a) $A_{\text {cap }}$

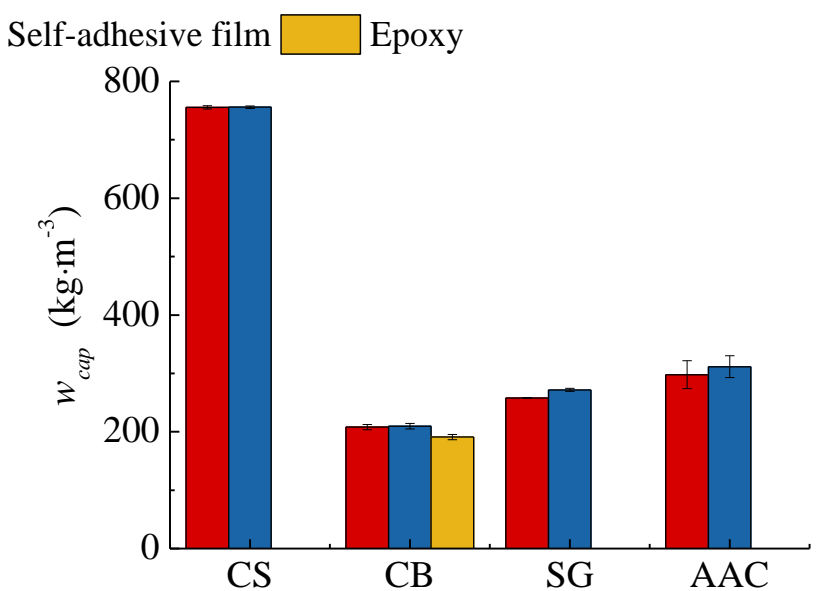

(b) $w_{c a p}$

Fig.3 Experimental results of samples sealed with different materials 
Postprint: Feng C, Janssen H. 2018. Hygric properties of porous building materials (III): impact factors and data processing methods of the capillary absorption test , Building and Environment, 134: 21-34.

doi: https://doi.org/10.1016/j.buildenv.2018.02.038

It is clearly shown in Fig.3 that for both $A_{\text {cap }}$ and $w_{\text {cap }}$ the non-adhesive film and self-adhesive film give similar results. For CS and CB the $A_{\text {cap }}$ results differ only around $1 \%$, which can be neglected reasonably. For AAC the relative difference of $A_{\text {cap }}$ reaches $15.1 \%$, greater than the repeatability errors. However, the paired T-test [34] proves that these two groups of experimental results are statistically the same (95\% confidence level). For SG the relative difference of $A_{\text {cap }}$ reaches $11.5 \%$, roughly double the repeatability errors, and statistical analysis this time fails to prove their similarity. However, since all other three materials don't suffer from great impact from different film sealing, this single case cannot assert the impropriety of the film sealing for $A_{\text {cap }}$ determination. In terms of $w_{\text {cap }}$, the non-adhesive film and self-adhesive film provide even closer results. For both CS and CB the differences are less than $1 \%$, while for SG and AAC around 5\%, all smaller than or comparable with experimental errors.

When it comes to CB samples sealed with epoxy, more than $8 \%$ reduction in both $A_{\text {cap }}$ and $w_{\text {cap }}$ is observed, far beyond the repeatability errors and statistical similarity. These systematic discrepancies must have a cause, and a highly plausible explanation is that epoxy penetrates into the sample before it solidifies, with this penetration reducing the effective cross-section size for the capillary absorption process. Simple calculations reveal that this extent of reduction can result from 1-1.5 mm of epoxy penetration, which is a reasonable assumption.

Besides possible penetration, coating the samples with paint or resin furthermore suffers from experimental inconvenience, inefficiency and non-safety. It is also difficult to recycle the painted samples for other tests. Thus, sealing the samples with films is more advisable, and both self-adhesive and non-adhesive films are acceptable.

\subsection{Initial moisture content}

According to Eq.(A1-4) and (A1-6) (see Appendix A), the initial moisture content ( $w_{i n i}, \mathrm{~kg} \cdot \mathrm{m}^{-3}$ ) has an impact on $A_{\text {cap }}$. This is also predicted by the diffusivity model [44]. Gummerson et al [42] suggested that for very delicate tests, $w_{i n i}$ should be uniform and known. Hall [45] believed that $w_{i n i}$ affected not only $A_{\text {cap }}$ but also the final moisture content. Janz [46] also quantitatively observed a negative correlation between wini and $A_{\text {cap }}$. Their remarks are reasonable, but valid mainly in the over-hygroscopic range where samples can have very high wini values, or for extremely hygroscopic materials in the hygroscopic range. If $w_{i n i}$ is relatively low, its impact on $A_{\text {cap }}$ should be negligible, as predicted by Eq. (A1-4) and (A1-6) and proved by the measurements conducted by Bomberg et al [27].

There is no doubt that it is preferable to indicate $w_{\text {ini }}$ when reporting on a measured $A_{\text {cap }}$ value. But its optimal choice for measurements can differ. For instance, the ISO 15148 standard [20] prescribes the pre-conditioning at an $\mathrm{RH}$ of $40 \%-60 \%$ until the total mass of the sample stabilizes to within $0.1 \%$ change over $24 \mathrm{~h}$. Plagge et al [47] preferred a pre-conditioning at $\mathrm{RH} 33 \%$ for 14 days, while Hall [45] suggested the oven-dried state to start with. From a broader point of view, the choice of $w_{i n i}$ should correspond with the application purpose. If the $A_{\text {cap }}$ is used to depict the in-situ performance of a building material/envelope in contact with liquid water (such as wind-driven rain), then pre-conditioning the material to a realistic wini may be advisable. If the $A_{c a p}$ is used for further material characterization - such as deriving the liquid diffusivity - then it is more reasonable to oven-dry the sample before the capillary absorption test. If the final purpose of the $A_{\text {cap }}$ experiment is undetermined, the oven-dried initial state is still the good choice, because of its simplicity, efficiency and comparability. 
Postprint: Feng C, Janssen H. 2018. Hygric properties of porous building materials (III): impact factors and data processing methods of the capillary absorption test , Building and Environment, 134: 21-34.

\subsection{Temperature}

Temperature is one of the most important conditions in laboratory control. In the ASTM C1585 standard [28] it is strictly stated that the capillary absorption test should be performed at $23 \pm 2{ }^{\circ} \mathrm{C}$. However, in the ISO 15148 standard [20] the tolerance is greater, ranging from $18^{\circ} \mathrm{C}$ to $28^{\circ} \mathrm{C}$ with a variation of $\pm 2^{\circ} \mathrm{C}$. Worse still, in the literature it is not always clear that at which temperatures the measurements were conducted. If the influence of temperature is not clarified, the comparison of different results and the practical use of $A_{c a p}$ may suffer from great uncertainty.

For the capillary absorption process, the classic Lucas-Washburn equation asserts that the influence of temperature is mainly exerted through its impact on the surface tension $\left(\gamma_{w}, \mathrm{~N} \cdot \mathrm{m}^{-1}\right)$ and the viscosity $\left(\mu_{w}, \mathrm{~Pa} \cdot \mathrm{s}\right)$ of water [48, 49]. By transforming the Lucas-Washburn equation the following equation for $A_{\text {cap }}$ can be obtained [21, 42, 46]:

$$
A_{\text {cap }} \propto \sqrt{\gamma_{w} / \mu_{w}}
$$

A further development of Eq.(2) shows that within $0-50^{\circ} \mathrm{C}$ the following equation can be used to assess the impact of temperature on $A_{\text {cap }}$ more quantitatively [25]:

$$
A_{\text {cap }}=k \cdot[0.095 \cdot(T-273.15)+6.566]
$$

Consequently, for a given material, the coefficient $k$ can be calculated if $A_{\text {cap }}$ at temperature $T(\mathrm{~K})$ is accurately known, and the $A_{\text {cap }}$ values at other temperatures can be subsequently predicted.

Recently Ioannou et al [21] proposed an F-scaling model to predict temperature's impact, wherein the factor $F=\left(\gamma_{w} / \mu_{w}\right)^{0.5}$. Although their fitting function is more complicated and thus more accurate than Eq.(3), their analysis is hence similarly based on the temperature variations of $\gamma_{w}$ and $\mu_{w}$.

There are, however, different opinions concerning temperature's impact. Mukhopadhyaya et al [50] measured the $A_{c a p}$ of eastern white pine, red clay brick and concrete between $3-35^{\circ} \mathrm{C}$. For eastern white pine (hence claimed weakly capillary materials) they found strong temperature dependency, while for red clay brick and concrete (and hence claimed strongly capillary materials) negligible impact from temperature was observed. As discussed in [25], such inconsistent findings mainly stem from their experimental protocol: Mukhopadhyaya et al only changed the water temperature but left the sample and room temperature unchanged. Consequently, the large thermal capacities of red clay brick and concrete can easily obscure the expected influence of temperature.

The tests performed by Karagiannis et al [23] on 10 different stones, bricks and mortars between $15-30^{\circ} \mathrm{C}$ made them cast doubt on the validity of Eq.(2). They found that some materials responded in agreement with Eq.(2) while others did not. Unfortunately, careful scrutiny of their publication [23] reveals not only several calculation mistakes but also dubious and self-contradictory data. Their data in different publications are also inconsistent [23, 51]. Last but not least, the data processing method adopted by the authors is also questionable. A re-interpretation with more appropriate method shows for 9 out of their 10 experimental cases Eq.(2) is valid, and the only exception results from extremely irregular absorption behavior. For more details on this debate, the readers are referred to [26, 52].

Despite the many limitations of the Lucas-Washburn equation, the generality of Eq.(2) has been validated by numerous independent tests $[25,42,53]$. Moreover, the above-mentioned counter-cases have their flaws. Thus, all convincing evidence supports the evaluation of temperature's impact on $A_{\text {cap }}$ primarily based on the temperature dependence of $\gamma_{w}$ and $\mu_{w}$.

When it comes to the temperature dependence of $w_{c a p}$, not much research has been conducted. Both the measurements performed by She and Sleep [54] on silica sand and our tests on CS, CB and AAC [25] show that the influence of temperature on $w_{c a p}$ is limited. This is also accepted by other 
Postprint: Feng C, Janssen H. 2018. Hygric properties of porous building materials (III): impact factors and data processing methods of the capillary absorption test , Building and Environment, 134: 21-34.

doi: https://doi.org/10.1016/j.buildenv.2018.02.038

researchers [21].

It should be noted that in our previous publications $[11,25,29]$ the irregular $1^{\text {st }}$ stage of AAC was fitted by Eq.(4) - the one-tangent method. With Eq.(8) as the improved method, the specific $A_{c a p}$ and $w_{c a p}$ values become different, but the impact of temperature remains steady.

\subsection{Personnel}

Different operators can obtain quite discrepant results due to their variance in experimental experience, criteria judgment, data processing and so on. To analyze the impact of personnel, the first author of this paper and another two researchers in KU Leuven have performed capillary absorption tests with the same apparatus on identical CB samples, following the same experimental procedure and data processing method. Their average $A_{\text {cap }}$ results of duplicate samples are $0.607,0.583$ and $0.590 \mathrm{~kg} \cdot \mathrm{m}^{-2} \mathrm{~s}^{-0.5}$ respectively, while for $w_{\text {cap }}$ they obtain $209.6,208.8$ and $206.3 \mathrm{~kg} \cdot \mathrm{m}^{-3}$ respectively. Clearly, the $A_{c a p}$ obtained by different operators have a relative standard deviation of $2.0 \%$, while for $w_{c a p}$ it is even as small as $0.8 \%$. The discrepancies between different operators are thus either comparable with repeatability errors or negligibly small. Consequently, we conclude that the impact of personnel on the capillary absorption test is very limited, so long as operators are trained properly and maintain consistency in all aspects concerning experimental protocol and data processing.

\section{Data processing methods for $A_{c a p}$}

This section focuses on the determination of $A_{\text {cap }}$ from experimental raw data. We will first define two distinct stages in the capillary absorption process and then classify ideal and irregular capillary absorption patterns according to the linearity of the $1^{\text {st }}$ stage. After that various data processing methods for deriving $A_{\text {cap }}$ from the $1^{\text {st }}$ stage will be summarized and compared. Finally, the best data processing method for $A_{c a p}$ will be recommended.

\subsection{Different capillary absorption patterns}

By subtracting the dry mass $\left(m_{d r y}, \mathrm{~kg}\right)$ from the wet mass $\left(m_{w e t}, \mathrm{~kg}\right)$ and then dividing by the bottom surface area $A$, the cumulative inflow $\left(\left(m_{\text {wet }}-m_{d r y}\right) / A, \mathrm{~kg} \cdot \mathrm{m}^{-2}\right)$ could be obtained. By drawing the cumulative inflow against the square root of time $\left(t^{0.5}, \mathrm{~s}^{0.5}\right)$, we can plot the capillary absorption process of the sample. As illustrated in Fig.4(a), the capillary absorption process of CS (and $\mathrm{CB}$, not illustrated here) can be ideally divided into a fast $1^{\text {st }}$ stage and a slow $2^{\text {nd }}$ stage. The $1^{\text {st }}$ stage is dominated by the capillary force when the water front has not reached the sample's top yet, while the $2^{\text {nd }}$ stage is mainly governed by the entrapped air diffusing out after the water front reached the sample top [55]. Both stages typically demonstrate linear relations between the cumulative inflow and the square root of time. Between the $1^{\text {st }}$ and the $2^{\text {nd }}$ stages, there may be an observable or negligible transition.

Not all materials behave so ideally during the $1^{\text {st }}$ stage though. As is clearly revealed in Fig.4(b), SG (and AAC, not illustrated here) shows a non-linear relationship between the cumulative inflow and the square root of time. This irregular pattern is also observed by numerous researchers on many other materials. It is commonly assumed that gravity is the primary reason [24, 43], but alternatively multi-pore-systems, pore swelling, component hydration and limited water source are also suggested $[23,24,56-58]$.

Whatever the capillary absorption process is, $A_{\text {cap }}$ is generally defined as the inflow divided by the square root of time during the $1^{\text {st }}$ stage. However, no consensus has been reached regarding the specific calculation method of $A_{c a p}$, especially when the behavior of the $1^{\text {st }}$ stage is irregular. In the following sections, we will summarize and compare various methods proposed by different scholars. 


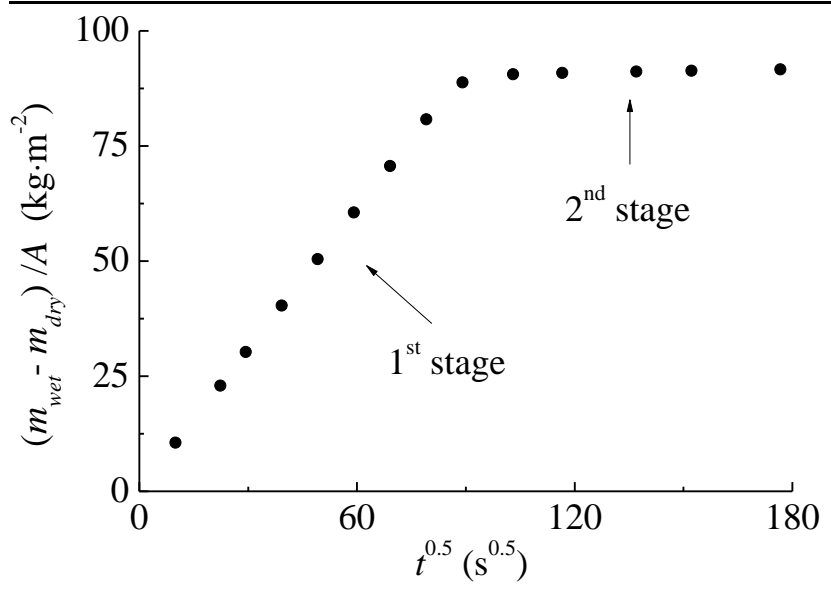

(a) CS: $A=32 \mathrm{~cm}^{2}, H=12 \mathrm{~cm}, 20.1^{\circ} \mathrm{C}$

doi: https://doi.org/10.1016/j.buildenv.2018.02.038

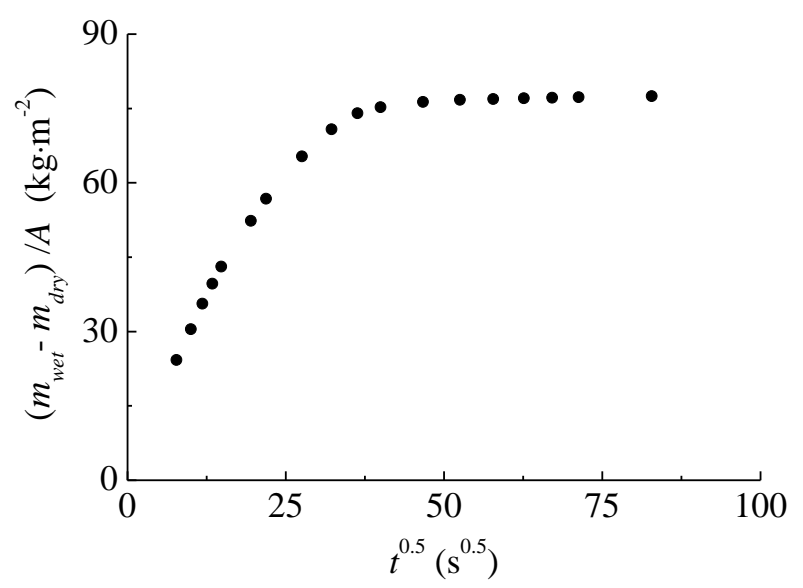

(b) SG: $A=23 \mathrm{~cm}^{2}, H=28 \mathrm{~cm}, 20.4^{\circ} \mathrm{C}$

Fig.4 Different capillary absorption patterns

\subsection{Review of different data processing methods for $\boldsymbol{A}_{\text {cap }}$}

\subsubsection{One-tangent method (linear regression)}

The most frequently adopted method is linear regression. By fitting Eq.(4) onto the data points, the slope can be obtained, and the capillary absorption coefficient is defined accordingly:

$$
\frac{m_{\text {wet }}-m_{d r y}}{A}=A_{\text {cap }} \cdot t^{0.5}+k_{1}
$$

where $k_{1}$ is the fitted intercept.

This linear regression method is also called the one-tangent method. It is adopted by numerous researchers [14, 21, 43, 47, 50, 53, 59] and also recommended by many standards, such as ISO 15148 [20], ASTM C1585 [28], BS EN 1925 [15] and EN 1015-18 [17]. The popularity of the one-tangent method partly lies in its solid physical foundation. Wilson et al [60] established Eq.(4) based on diffusivity, while we introduce a permeability-based model in Appendix 1.

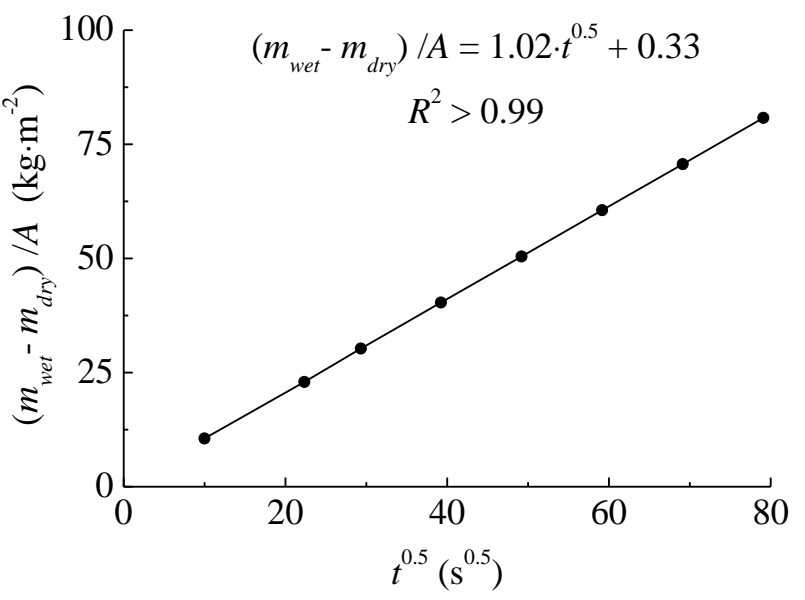

Fig.5 One-tangent method for calculating the $A_{\text {cap }}$ of CS

Fig.5 illustrates the successful application of the one-tangent method to a CS sample, with the coefficient of determination $R^{2}$ extremely close to 1 . It should be mentioned that the intercept $k_{1}$ of Eq.(4) is not necessarily 0, meaning that the fitted straight line doesn't necessarily pass through the origin. A positive intercept indicates a faster inflow during the initial period. There is experimental 
Postprint: Feng C, Janssen H. 2018. Hygric properties of porous building materials (III): impact factors and data processing methods of the capillary absorption test , Building and Environment, 134: 21-34.

doi: https://doi.org/10.1016/j.buildenv.2018.02.038

evidence showing the positive correlation between the intercept and the immersion depth [60], which can be partly explained by the sudden filling of the bottom and lateral open pores [43], as well as the multidimensional inflow from the immersed lateral sides [60]. On the contrary, it is also possible to observe a negative intercept, indicating a delay or acceleration of capillary absorption. Songok et al [48] summarized that the inertial resistance can play a significant role during the early stage, especially for large pores and small liquid viscosity. Thanks to the joint effect of all these factors, some points in the initial period of the $1^{\text {st }}$ stage may deviate noticeably from the expected linear behavior. These outliers, if exist, should be discarded during the linear fitting process.

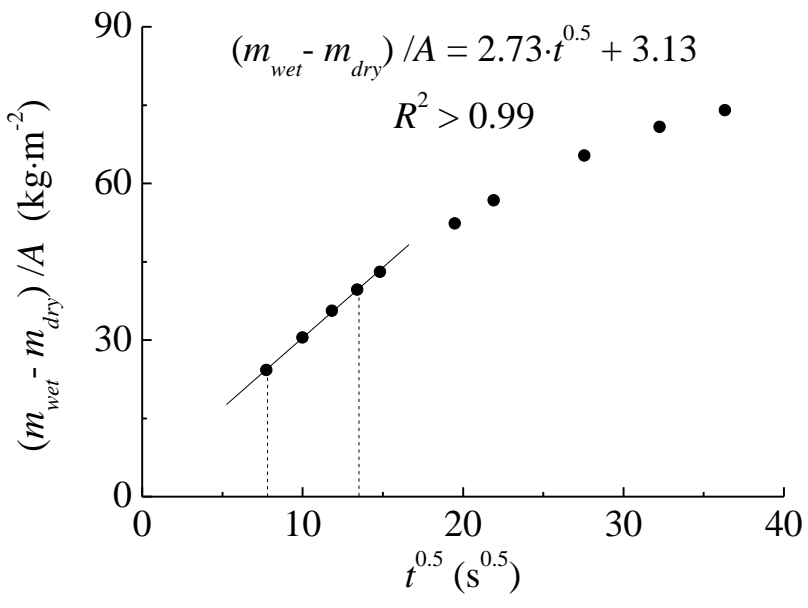

(a) First 4 points

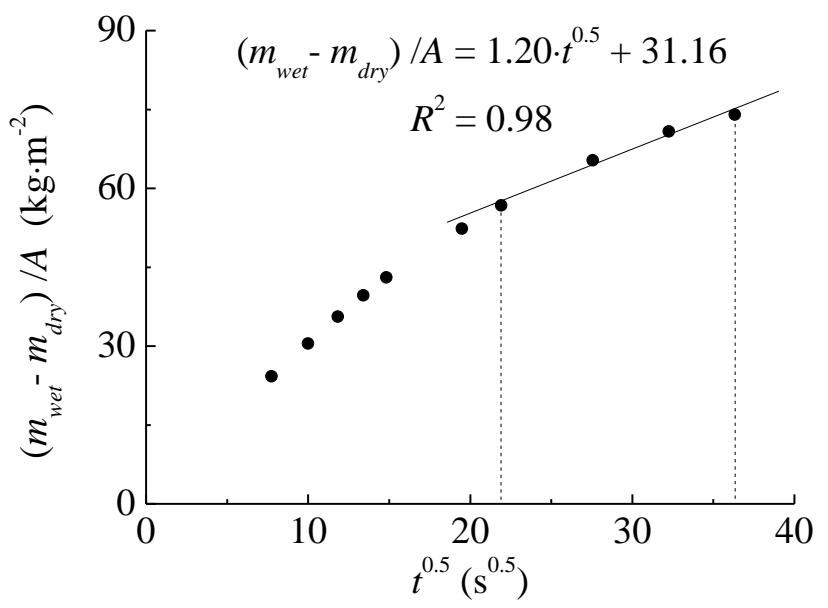

(b) Last 4 points

Fig.6 One-tangent method for calculating the $A_{\text {cap }}$ of SG with different data selections

When the $1^{\text {st }}$ stage is ideally linear, this method is advisable due to its simplicity and solid physical background. However, when the $1^{\text {st }}$ stage strongly deviates from the linear behavior, the fitting result becomes very sensitive to data selection. Fig.6 illustrates the case for SG. Clearly, the slopes can differ as much as a factor of 2.3 , making the determination of $A_{\text {cap }}$ very arbitrary. The one-tangent method is therefore not suitable for such cases.

\subsubsection{Modified one-tangent method}

By plotting $\mathrm{d}\left[\left(m_{\text {wet }}-m_{d r y}\right) / A\right] / \mathrm{d} t^{0.5}$ against $t^{0.5}$, the experimental results can be expressed in another way, as suggested by Bomberg et al [27] and their followers [61]. Since measurements only provide discrete points, the derivative $\mathrm{d}\left[\left(m_{w e t}-m_{d r y}\right) / A\right] / \mathrm{d} t^{0.5}$ can only be replaced by the finite difference between successive measurements. It is not clear whether the forward, backward or central difference is preferred, but the choice should have minimal impact. With this method, Fig.5 can be transformed into Fig.7 (the backward difference is used here).

This method is fundamentally a variation of the one-tangent method, so we name it as the modified one-tangent method. Since it relies on the one-tangent method, it is resultantly neither suitable for irregular patterns. However, even if the $1^{\text {st }}$ stage of the capillary absorption process is ideal, the modified one-tangent method still lacks overwhelming advantages over the one-tangent method. Bomberg et al [27] claimed that it "showed a greater sensitivity and displayed individual variations that were not visible in the cumulative plots used in the traditional manner...". This is indeed true, as the residuals in the linear fitting are directly transformed into the fluctuation of $\mathrm{d}\left[\left(m_{\text {wet }}-m_{d r y}\right) / A\right] / \mathrm{d} t^{0.5}$ in Fig.7, representing the variability of $A_{c a p}$. However, it is not clear how $A_{c a p}$ is finally calculated. Most probably is that the arithmetic mean value of $\mathrm{d}\left[\left(m_{\text {wet }}-m_{d r y}\right) / A\right] / \mathrm{d} t^{0.5}$ in the 
Postprint: Feng C, Janssen H. 2018. Hygric properties of porous building materials (III): impact factors and data processing methods of the capillary absorption test , Building and Environment, 134: 21-34.

doi: https://doi.org/10.1016/j.buildenv.2018.02.038

$1^{\text {st }}$ stage is taken as $A_{\text {cap. }}$. As proved in Appendix 2, the traditional one-tangent method (linear fitting) is mathematically superior to the modified one-tangent method.

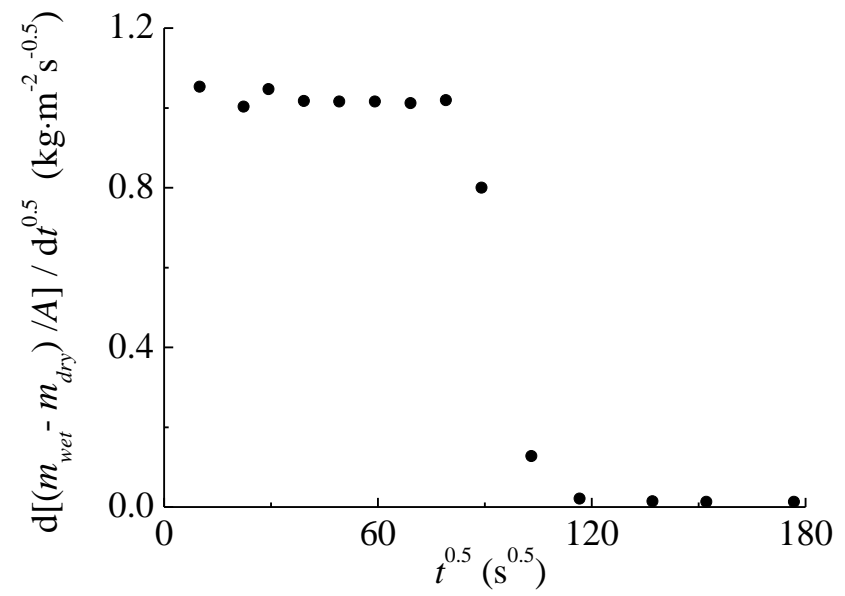

Fig.7 Modified one-tangent method for calculating the $A_{\text {cap }}$ of CS

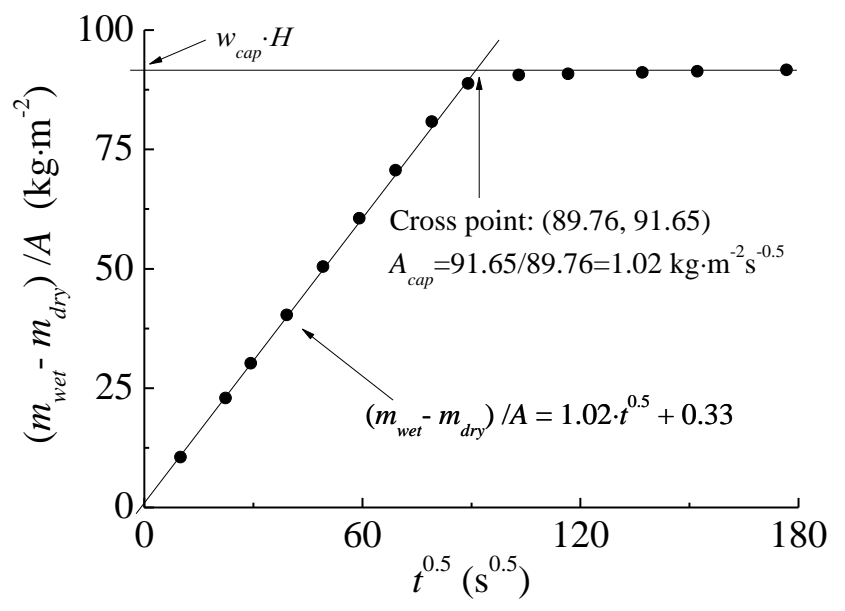

Fig.8 Two-tangent method for calculating the $A_{\text {cap }}$ of CS

\subsubsection{Two-tangent method}

The Italian Normal 11/85 [19] proposes another method for determining $A_{\text {cap. }}$ According to this method, the measurement should continue until the increase of the cumulative inflow $\left(m_{w e t}-m_{d r y}\right) / A$ (or the absorb moisture $m_{w e t}-m_{d r y}$ ) is less than $1 \%$ over 24 hours. Then the first tangent $y=y_{\text {cross }}$ is drawn with $y_{\text {cross }}$ representing the final cumulative inflow. Next, the second tangent is drawn by fitting the data in the $1^{\text {st }}$ stage linearly, the same as the one-tangent method. These two straight lines intersect each other at the cross point $\left(x_{\text {cross }}, y_{\text {cross }}\right)$, and the capillary absorption coefficient is derived as:

$$
A_{\text {cap }}=\frac{y_{\text {cross }}}{x_{\text {cross }}}
$$

Since two tangents are involved in this method, it can be named as the two-tangent method, as illustrated in Fig.8.

Despite its advocates $[23,51]$, the two-tangent method still suffers from several defects. First and foremost, the stopping criterion of this method indicates that if the measurement is terminated before reaching the $2^{\text {nd }}$ stage, then $A_{c a p}$ cannot be calculated. In practice, if $A_{c a p}$ (without $w_{c a p}$ ) is the only target in the capillary absorption test, it would be much more efficient to conduct measurements only during the $1^{\text {st }}$ stage, as in the ASHRAE Research Project 1018-RP [12]. Moreover, it is widely acknowledged that $A_{\text {cap }}$ depicts the rate of water absorption driven by the capillary force during the $1^{\text {st }}$ stage, while the introduction of the final absorption amount after the sample reaching its capillary moisture content makes the definition ambiguous. In addition, the stopping criterion cannot always be fulfilled in reality, not only in our measurements but also in the measurements conducted by its advocates on many other materials [23, 51]. Even if the stopping criterion is satisfied, it can be expected that the $A_{c a p}$ from the two-tangent method may differ significantly from the $A_{c a p}$ from the one-tangent method, especially when the intercept of the $1^{\text {st }}$ stage fitting is far from 0 . Finally, the incapability of the one-tangent method - the basis of the two-tangent method - to process irregular $1^{\text {st }}$ stage data naturally invalidates the application of the two-tangent method in handling such cases. 
Postprint: Feng C, Janssen H. 2018. Hygric properties of porous building materials (III): impact factors and data processing methods of the capillary absorption test , Building and Environment, 134: 21-34.

\subsubsection{Fix-time method (one-point/single-point method)}

A fourth protocol can be generalized as the fix-time method. For this method, the wet mass $m_{w e t}$ is measured just once at a prescribed time $t=t_{\text {end }}$ during the capillary absorption process. Then $A_{\text {cap }}$ is calculated according to Eq.(6):

$$
A_{c a p}=\left.\frac{\left(m_{w e t}-m_{d r y}\right) / A}{t^{0.5}}\right|_{t=t_{\text {end }}}
$$

Since only one point during the capillary absorption process is used, this method can also be named as the one-point method or the single-point method. The prescribed $t_{\text {end }}$ can be different, ranging from 1 minute to half an hour, or even as long as $24 \mathrm{~h}[16,18,20,60]$, but the basic principle remains the same. Fig.9(a) illustrates the result for a CS sample with $t_{e n d}=30 \mathrm{~min}$ (prescribed in the former Italian UNI 10859 standard [16], now superseded by the UNI EN 15801 standard [18]).

In Fig.5 and 9(a), the $A_{\text {cap }}$ of CS obtained from the fix-time method is in nice agreement with that from the one-tangent method. Unfortunately, such coincidence can occur only when the $1^{\text {st }}$ stage is perfectly linear, the intercept from the linear fitting is almost 0 , and the timing is without large errors. Otherwise, significant discrepancies can be expected, as experimentally revealed by Wilson et al [60].

A vital defect also exists for the fix-time method: the difficulty for prescribing a proper ending time $t_{e n d}$. For a material with large $A_{c a p}$, the sample must be tall enough to ensure that the measurement stops within the $1^{\text {st }}$ stage. For a material with small $A_{c a p}$, on the other hand, it requires an extremely long time for reliable determination. The proper selection of $t_{e n d}$, unfortunately, depends on many factors such as material, sample height, experimental temperature, multidimensional inflow and so on, making a consistent $t_{\text {end }}$ choice almost impossible. If the $1^{\text {st }}$ stage is irregular, the situation is even worse. In Fig.9(b) we compare the results from the same raw data with different tend. Besides the 30 min prescribed by the Italian standards $[16,18]$, the $24 \mathrm{~h}$ suggested by the ISO 15148 standard [20] is also used. As is clearly revealed, different $t_{\text {end }}$ leads to significantly discrepant $A_{\text {cap }}$, making the fix-time method inadvisable.

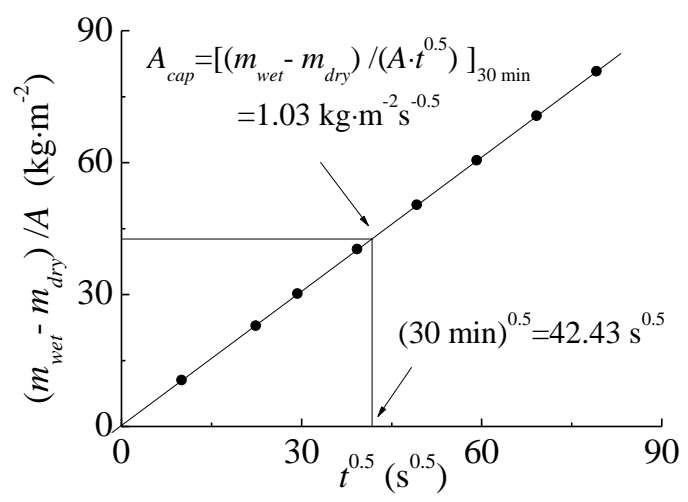

(a) Application on CS with $t_{\text {end }}=30 \mathrm{~min}$

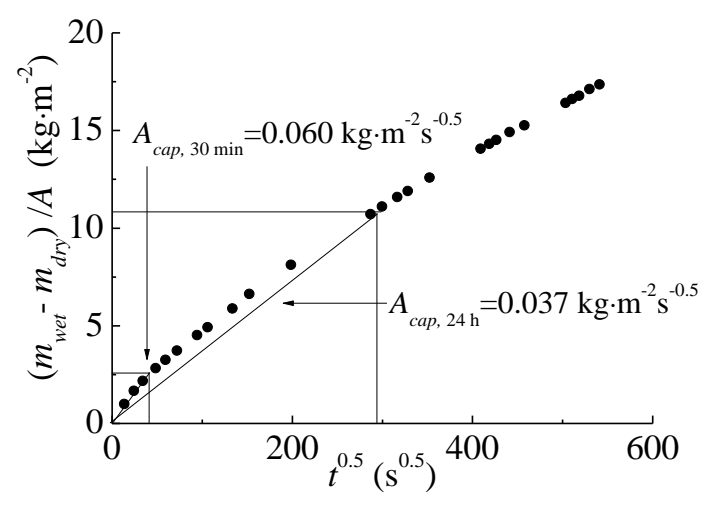

(b) Application on AAC with different $t_{\text {end }}$

Fig.9 Fix-time method for calculating the $A_{\text {cap }}$

\subsubsection{Hall's method and our new model}

When gravity plays a non-negligible role, Hall [43, 45] suggested the following equation, which can be justified by both the unsaturated flow theory and the "sharp front" theory: 
Postprint: Feng C, Janssen H. 2018. Hygric properties of porous building materials (III): impact factors and data processing methods of the capillary absorption test , Building and Environment, 134: 21-34.

doi: https://doi.org/10.1016/j.buildenv.2018.02.038

$$
\frac{m_{w e t}-m_{d r y}}{A}=A_{c a p} \cdot t^{0.5}+k_{1}-k_{2} \cdot t
$$

where $k_{1}$ and $k_{2}$ are fitting parameters. Obviously, the term $-k_{2} \cdot t$ of Eq.(7) accounts for the cumulative contribution of gravity. Although Hall's method was proposed for non-linear situations with gravity taken into account, it is also suitable for linear cases: as the parameter $k_{2}$ approaches 0, Eq.(7) becomes identical to Eq.(4).

Besides Hall's method, we also propose a new model for determining $A_{c a p}$ for the irregular pattern:

$$
\frac{m_{w e t}(t)-m_{d r y}}{A}=A_{c a p} \cdot k_{3} \cdot\left(0.5103-1.3849 \cdot e^{-\frac{t}{k_{3}^{2}-1}}\right)^{0.3403}+k_{4}
$$

where $k_{3}$ and $k_{4}$ are also fitting parameters. This model has a similarly solid physical background and is simplified from the Lambert $W$-function [62]. We leave the detailed deduction for Appendix 1.

The application of Hall's method and our new model to SG are illustrated in Fig.10. Both methods are proposed with solid physical backgrounds, taking gravity into account. As illustrated in Fig.11, for irregular cases (SG and AAC) the results obtained from both methods are very close to each other, with relative differences around $10 \%$, which are in the same order of magnitude as the material inhomogeneity and experimental repeatability errors. Since Eq.(7) and Eq.(8) are deduced from different processes, the almost-the-same results indicate that both methods provide reasonable results. The fact that for both methods the $R^{2}$ in the fitting processes of all samples remains greater than 0.99 gives further support.

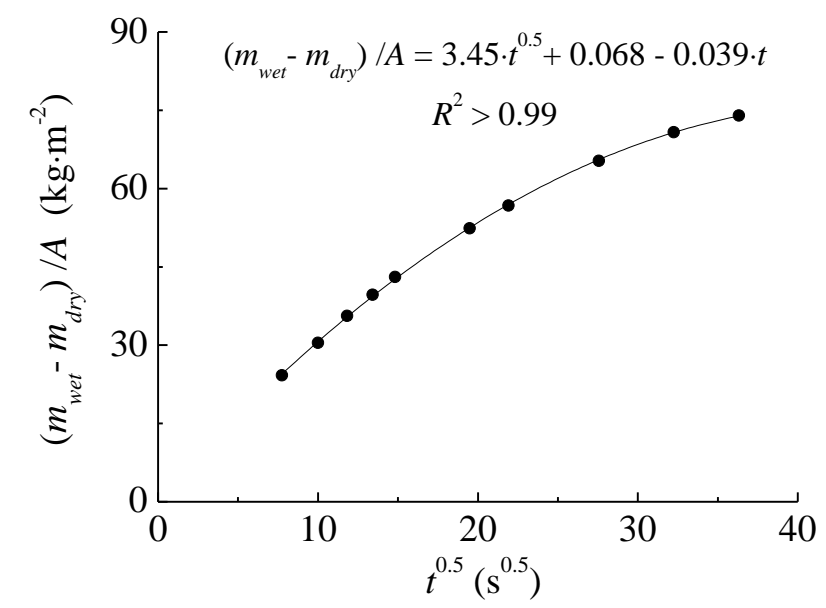

(a) Hall's method [43, 45]

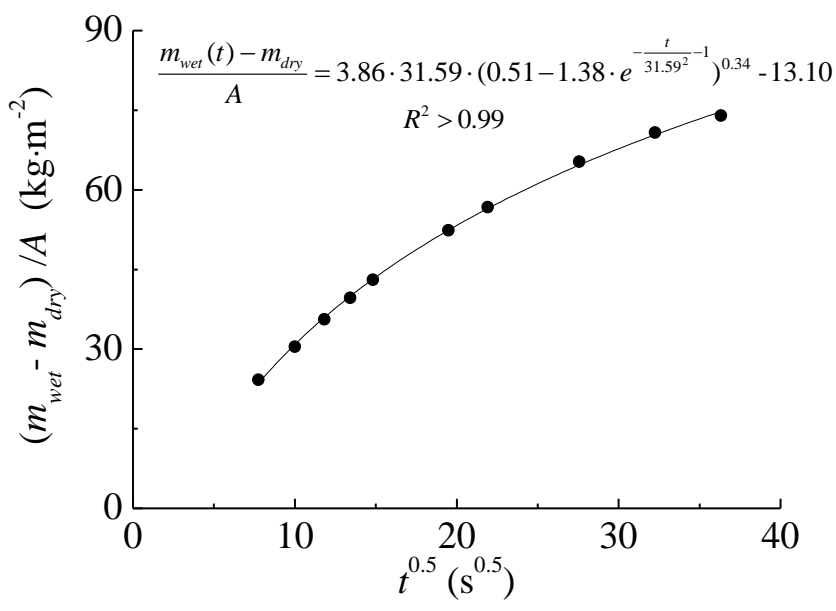

(b) Our new method

Fig.10 Calculations for the $A_{\text {cap }}$ of SG

More encouragingly, these two methods also work well with ideal cases. It is clearly reflected in Fig.11 that for CS and CB, Hall's method and our new method derive almost identical results as the one-tangent method. Specifically, with the results from the one-tangent method as a reference, the $A_{\text {cap }}$ values of CS and CB calculated with Hall's method deviate $-4.9 \%$ and $-5.3 \%$, respectively. Our new method produces even closer results, deviating $-2.8 \%$ and $-0.9 \%$, respectively.

In practice, it is not always clear beforehand whether a test material has an ideal or irregular absorption pattern. A one-size-fits-all strategy is thus to use either Hall's or our new method to process the raw data directly, be it ideal or irregular. Since Eq.(7) is mathematically simpler than Eq.(8), Hall's method seems more favorable. However, as will be demonstrated in the next section, Hall's method may encounter difficulties in deriving $w_{c a p}$. In addition, with the help of modern 
Postprint: Feng C, Janssen H. 2018. Hygric properties of porous building materials (III): impact factors and data processing methods of the capillary absorption test , Building and Environment, 134: 21-34.

doi: https://doi.org/10.1016/j.buildenv.2018.02.038

computers, the application of Eq.(8) is not a daunting task at all.

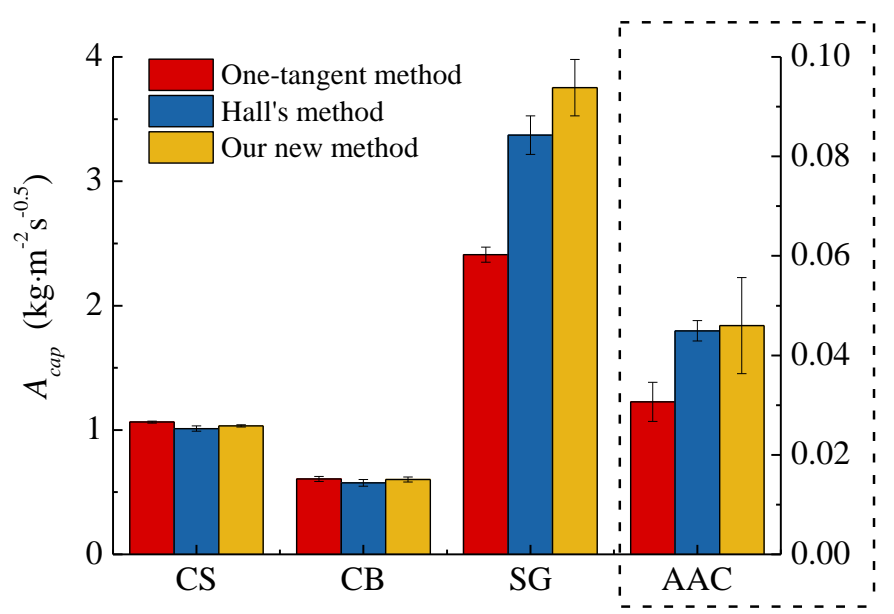

Fig.11 $A_{\text {cap }}$ obtained from different methods

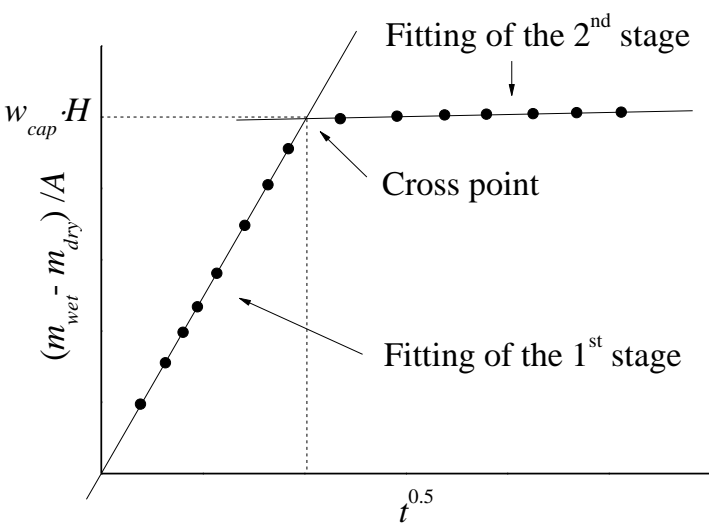

Fig.12 The determination of $w_{c a p}$

\section{Data processing methods for $w_{c a p}$}

Compared to the capillary absorption coefficient $A_{\text {cap }}$, the capillary moisture content $w_{c a p}$ is not always addressed in standards. For instance, the ISO 15148 standard prescribes that if water appears on the top of the sample, then the test should be terminated [20]. Consequently, $w_{c a p}$ is not involved at all. In the ASTM C1585 standard [28], two phases of the capillary absorption process are expected. However, the standard suggests fitting both phases linearly and then defines these slopes respectively, without mentioning $w_{\text {cap }}$.

In research sources on the other hand, such as journal articles and conference proceedings, $w_{c a p}$ is frequently used, hence calling for its clear definition. Fortunately, there are far fewer controversies over it. In most cases, $w_{c a p}$ is defined as the moisture content at the transition from the $1^{\text {st }}$ to the $2^{\text {nd }}$ stage $[47,59,63]$. Specifically, it is the moisture content corresponding to the cross point of the fittings for the $1^{\text {st }}$ and the $2^{\text {nd }}$ stages, as illustrated in Fig. 12 .

As suggested in the ASTM C1585 standard [28], the $2^{\text {nd }}$ stage can be fitted linearly. Then the cross point with the fitting of the $1^{\text {st }}$ stage can be calculated and the $w_{c a p}$ can be derived by dividing the cumulative inflow (the y-coordinate) of the crosspoint by the sample height $H(\mathrm{~m})$ :

$$
w_{\text {cap }}=\left.\frac{m_{\text {wet }}-m_{d r y}}{A}\right|_{\text {cross }} \cdot \frac{1}{H}
$$

Hall's method was originally and successfully proposed for the $1^{\text {st }}$ stage only, without intention for extrapolation. If it is used to fit the $1^{\text {st }}$ stage and extrapolate for $w_{c a p}$ thereafter, one problem may appear. Eq.(7) is fundamentally a quadratic function with $t^{0.5}$ as the independent variable. This quadratic function starts decreasing after reaching the apex, thus there is possibly no cross point between the fitted quadratic function and the linear function for the $2^{\text {nd }}$ stage, making the determination of $w_{c a p}$ impossible. According to our measurements on SG and AAC, almost half cases suffer from this situation.

On the contrary, Eq.(8) monotonically increases with $t$, meaning the fitted curve definitely has a single cross point with the linear fitting of the $2^{\text {nd }}$ stage, making the determination of $w_{c a p}$ always possible. As demonstrated in Section 4.2.5, our new method is also applicable to the ideal capillary 
Postprint: Feng C, Janssen H. 2018. Hygric properties of porous building materials (III): impact factors and data processing methods of the capillary absorption test , Building and Environment, 134: 21-34.

doi: https://doi.org/10.1016/j.buildenv.2018.02.038

absorption pattern. Consequently, by far the most troubleless data processing method for all cases is always applying our new method directly to the $1^{\text {st }}$ stage, for the calculation of both $A_{\text {cap }}$ and $w_{\text {cap }}$.

\section{Conclusions}

This paper studies the potential impact factors and different data processing methods for deriving the capillary absorption coefficient $A_{c a p}$ and the capillary moisture content $w_{c a p}$ from the capillary absorption test. Measurements on calcium silicate, ceramic brick, autoclaved aerated concrete and sintered glass are carried out, and published literature results are reviewed for analysis. Following conclusions have been drawn:

(1) A bottom surface area of $15-20 \mathrm{~cm}^{2}$ for an individual sample should suffice in most cases, if the material is not extremely inhomogeneous and/or does not contain coarse elements. The sample height should be chosen according to the $A_{c a p}$ of the material and the desired experimental duration, as well as the handling convenience;

(2) Sealing test samples with films is more advisable than coating them with paint or resin, and both self-adhesive and non-adhesive films are acceptable;

(3) The choice of initial moisture content wini should correspond with the application purpose of $A_{\text {cap }}$. For in-situ performance depiction, the pre-condition to a realistic wini is advisable, while for general material property characterization the oven-dried state is more reasonable. For undefined usages, the oven-dried state is recommended for its simplicity, efficiency and comparability;

(4) Temperature affects $A_{\text {cap }}$ by changing the surface tension and the viscosity of water. Within $0-50^{\circ} \mathrm{C}$ Eq.(3) can be used for quantitative assessment. $w_{c a p}$ is not sensitive to common temperature variations;

(5) The impact of personnel on the capillary absorption test is very limited, so long as operators are trained properly and maintain consistency in all aspects concerning experimental protocol and data processing;

(6) A new physical model has been proposed to process the experimental data for calculating both $A_{\text {cap }}$ and $w_{\text {cap }}$. It is applicable to both ideal and irregular capillary absorption patterns, and it shows superiorities to other published models.

\section{Acknowledgements}

This project is supported by the FWO Odysseus grant "Moisture transfer in building materials: analysis at the pore-scale level" (No. G.0C55.13N) and National Natural Science Foundation of China (No.51508542). The authors express their sincere gratitude to Jelena Todorović and Vasilis Soulios for sharing their experimental data.

\section{References}

[1] Vereecken E, Van Gelder L, Janssen H, Roels S. Interior insulation for wall retrofitting - A probabilistic analysis of energy savings and hygrothermal risks. Energy and Buildings. 2015;89:231-44.

[2] Harrestrup M, Svendsen S. Full-scale test of an old heritage multi-storey building undergoing energy retrofitting with focus on internal insulation and moisture. Building and Environment. 2015;85:123-33.

[3] Huijbregts Z, Schellen H, van Schijndel J, Ankersmit B. Modelling of heat and moisture induced strain to assess the impact of present and historical indoor climate conditions on mechanical degradation of a wooden cabinet. Journal of Cultural Heritage. 2015;16:419-27.

[4] Tittarelli F, Giosuè C, Mobili A, Ruello ML. Influence of binders and aggregates on VOCs adsorption and moisture 
Postprint: Feng C, Janssen H. 2018. Hygric properties of porous building materials (III): impact factors and data processing methods of the capillary absorption test , Building and Environment, 134: 21-34.

doi: https://doi.org/10.1016/j.buildenv.2018.02.038

buffering activity of mortars for indoor applications. Cement and Concrete Composites. 2015;57:75-83.

[5] Kwiatkowski J, Woloszyn M, Roux J-J. Influence of sorption isotherm hysteresis effect on indoor climate and energy demand for heating. Applied Thermal Engineering. 2011;31:1050-7.

[6] Geving S, Holme J. Mean and diurnal indoor air humidity loads in residential buildings. Journal of Building Physics. 2012;35:392-421.

[7] Funk M, Wakili KG. Driving potentials of heat and mass transport in porous building materials: a comparison between general linear, thermodynamic and micromechanical derivation schemes. Transport in Porous Media. 2008;72:273-94.

[8] Hens H, Ojanen T, Künzel HM, Dow G, Rode C, Hagentoft C. IEA Annex 24: Heat, Air and Moisture Transfer in Insulated Envelope Parts. Final Report, Volume 1, Task 1: Modeling. 1996.

[9] Woloszyn M, Rode C. IEA Annex 41: Whole Building Heat, Air, Moisture Response. Subtask 1: Modeling Principles and Common Exercises. 2008.

[10] Plagge R, Scheffler G, Nicolai A. Experimental methods to derive hygrothermal material functions for numerical simulation tools. Building $X$ Conference. Clearwater, Florida. 2007. p. 1-12.

[11] Feng C, Janssen H, Feng $\mathrm{Y}$, Meng Q. Hygric properties of porous building materials: Analysis of measurement repeatability and reproducibility. Building and Environment. 2015;85:160-72.

[12] Kumaran MK. A Thermal and Moisture Transport Property Database for Common Building and Insulating Materials, Final Report from ASHRAE Research Project 1018-RP. 2002.

[13] Roels S, Carmeliet J, Hens H, Adan O, Brocken H, Cerny R, Pavlik Z, Ellis AT, Hall C, Kumaran K. A comparison of different techniques to quantify moisture content profiles in porous building materials. Journal of Thermal Envelope and Building Science. 2004;27:261.

[14] Roels S, Carmeliet J, Hens H, Adan O, Brocken H, Czerny R, Hall C, Hamilton A, Kumaran K, Pavlik Z, Pel L, Plagge R, Tariku F. HAMSTAD Work Package 1: Final Report - Moisture Transfer Properties and Materials Characterisation, EU Contract GRD1-1999-20007. 2003.

[15] BS EN 1925:1999: Natural stone test methods. Determination of water absorption coefficient by capillarity. 1999.

[16] UNI 10859:2000: Cultural Heritage - Natural And Artificial Stones - Determination Of Water Absorption By Capillarity. 2000.

[17] BS EN 1015-18:2002: Methods of test for mortar for masonry. Determination of water absorption coefficient due to capillary action of hardened mortar. 2002.

[18] UNI EN 15801:2010: Conservation Of Cultural Property - Test Methods - Determination Of Water Absorption By Capillarity. 2010.

[19] NORMAL R. 11/85, Assorbimento d'acqua per capillarita. Coefficiente di assorbimento capillare, Consiglio Nazionale delle Ricerche, Istituto Centrale Restauro, Rome. 1985.

[20] ISO 15148: 2002(E) Hygrothermal performance of building materials and products-determination of water absorption coefficient by partial immersion. 2002.

[21] Ioannou I, Charalambous C, Hall C. The temperature variation of the water sorptivity of construction materials. Materials and Structures. 2017;50:208-19.

[22] Tsunazawa Y, Yokoyama T, Nishiyama N. An experimental study on the rate and mechanism of capillary rise in sandstone. Progress in Earth and Planetary Science. 2016;3:8-17.

[23] Karagiannis N, Karoglou M, Bakolas A, Moropoulou A. Effect of temperature on water capillary rise coefficient of building materials. Building and Environment. 2016;106:402-8.

[24] Hanžič L, Kosec L, Anžel I. Capillary absorption in concrete and the Lucas-Washburn equation. Cement and Concrete Composites. 2010;32:84-91.

[25] Feng C, Janssen H. Hygric properties of porous building materials (II): Analysis of temperature influence. Building 
Postprint: Feng C, Janssen H. 2018. Hygric properties of porous building materials (III): impact factors and data processing methods of the capillary absorption test , Building and Environment, 134: 21-34.

doi: https://doi.org/10.1016/j.buildenv.2018.02.038

and Environment. 2016;99:107-18.

[26] Feng $C$, Janssen $\mathrm{H}$. The influence of temperature on the capillary absorption coefficient-a confrontation of two recent papers in Building and Environment. Building and Environment. 2017;116:257-8.

[27] Bomberg M, Pazera M, Plagge R. Analysis of Selected Water Absorption Coefficient Measurements. Journal of Building Physics. 2005;28:227-43.

[28] ASTM C1585 - 13: Standard Test Method for Measurement of Rate of Absorption of Water by Hydraulic-Cement Concretes. 2013.

[29] Feng C, Janssen H, Feng Y, Meng Q. Experimental analysis of the repeatability of vacuum saturation and capillary absorption tests. $\quad$ 10th Nordic Symposium on Building Physics. Lund, Sweden. 2014. p. 394-401.

[30] ISO 12572: 2001(E) Hygrothermal performance of building materials and products - Determination of water vapour transmission properties. 2001.

[31] ISO 12571: 2000(E) Hygrothermal performance of building materials and products - Determination of hygroscopic sorption properties. 2000.

[32] Gao Z, Hu Q. Estimating permeability using median pore-throat radius obtained from mercury intrusion porosimetry. Journal of Geophysics and Engineering. 2013;10:025014.

[33] ISO 5725-2: 1994(E) Accuracy (trueness and precision) of measurement methods and results - Part 2: Basic method for the determination of repeatability and reproducibility of a standard measurement method. 1994.

[34] Montgomery DC. Design and analysis of experiments. 5th Edition. New York: John Wiley \& Sons Inc; 2008.

[35] Klisińska-Kopacz A, Tišlova R. Effect of hydrophobization treatment on the hydration of repair Roman cement mortars. Construction and Building Materials. 2012;35:735-40.

[36] Dias WPS. Reduction of concrete sorptivity with age through carbonation. Cement and Concrete Research. 2000;30:1255-61.

[37] Siddique R. Compressive strength, water absorption, sorptivity, abrasion resistance and permeability of self-compacting concrete containing coal bottom ash. Construction and Building Materials. 2013;47:1444-50.

[38] Kubissa W, Jaskulski R. Measuring and Time Variability of The Sorptivity of Concrete. Procedia Engineering. 2013;57:634-41.

[39] Leung HY, Kim J, Nadeem A, Jaganathan J, Anwar MP. Sorptivity of self-compacting concrete containing fly ash and silica fume. Construction and Building Materials. 2016;113:369-75.

[40] Zhao J, Plagge R. Characterization of hygrothermal properties of sandstones-Impact of anisotropy on their thermal and moisture behaviors. Energy and Buildings. 2015;107:479-94.

[41] Vázquez P, Alonso FJ, Esbert RM, Ordaz J. Ornamental granites: Relationships between p-waves velocity, water capillary absorption and the crack network. Construction and Building Materials. 2010;24:2536-41.

[42] Gummerson RJ, Hall C, Hoff WD. Water movement in porous building materials--II. Hydraulic suction and sorptivity of brick and other masonry materials. Building and Environment. 1980;15:101-8.

[43] Hall C, Tse TK-M. Water movement in porous building materials--VII. The sorptivity of mortars. Building and Environment. 1986;21:113-8.

[44] Hall C, Hoff W, Skeldon M. The sorptivity of brick: dependence on the initial water content. Journal of Physics D: Applied Physics. 1983;16:1875.

[45] Hall C. Water sorptivity of mortars and concretes: a review. Magazine of concrete research. 1989;41:51-61.

[46] Janz M. Methods of measuring the moisture diffusivity at high moisture levels. Lund Institute of Technology, Division of Building Materials, Lund. 1997.

[47] Plagge R, Scheffler G, Grunewald J. Automatic measurement of water uptake coefficient of building materials. Proceedings of 7th conference of building physics in Northern Countries. Reykjavik. 2005. p. 15-22.

[48] Songok J, Salminen P, Toivakka M. Temperature effects on dynamic water absorption into paper. Journal of Colloid 
Postprint: Feng C, Janssen H. 2018. Hygric properties of porous building materials (III): impact factors and data processing methods of the capillary absorption test , Building and Environment, 134: 21-34.

doi: https://doi.org/10.1016/j.buildenv.2018.02.038

and Interface Science. 2014;418:373-7.

[49] Washburn EW. The dynamics of capillary flow. Physical review. 1921;17:273-83.

[50] Mukhopadhyaya P, Kumaran K, Normandin N, Goudreau P. Effect of surface temperature on water absorption coefficient of building materials. Journal of Thermal Envelope and Building Science. 2002;26:179-95.

[51] Karagiannis N, Karoglou M, Bakolas A, Moropoulou A. Building Materials Capillary Rise Coefficient: Concepts, Determination and Parameters Involved. New Approaches to Building Pathology and Durability: Springer; 2016. p. 27-44.

[52]

https://www.researchgate.net/publication/312147868 The influence of temperature on the capillary absorption c oefficient - a comment on a recent paper by $\mathrm{N}$ Karagiannis et al.

[53] Reinhardt H-W, Jooss M. Permeability, Diffusion, and Capillary Absorption of Concrete at Elevated Temperature in the Service Range. Otto-Graf-Journal. 1998;9:34-47.

[54] She HY, Sleep BE. The effect of temperature on capillary pressure-saturation relationships for air-water and perchloroethylene-water systems. Water Resources Research. 1998;34:2587-97.

[55] Janssen H, Vereeckena E, Holúbek M. A confrontation of two concepts for the description of the overcapillary moisture range: air entrapment versus low capillarity. Energy Procedia. 2015;78:1490-4.

[56] Taylor S, Hoff W, Wilson M, Green K. Anomalous water transport properties of Portland and blended cement-based materials. Journal of materials science letters. 1999;18:1925-7.

[57] Hearn N, Detwiler RJ, Sframeli C. Water permeability and microstructure of three old concretes. Cement and concrete research. 1994;24:633-40.

[58] Hanžič L, Ilić R. Relationship between liquid sorptivity and capillarity in concrete. Cement and concrete research. 2003;33:1385-8.

[59] Nikitsin VI, Backiel-Brzozowska B. Determining hydraulic radii of construction wall materials in capillary moisture transfer. International Journal of Heat and Mass Transfer. 2015;88:558-64.

[60] Wilson M, Carter M, Hoff W. British Standard and RILEM water absorption tests: A critical evaluation. Materials and Structures. 1999;32:571-8.

[61] Zelinka SL, Glass SV, Boardman CR. Improvements to Water Vapor Transmission and Capillary Absorption Measurements in Porous Materials. Journal of Testing and Evaluation. 2016;44:2396-402.

[62] https://en.wikipedia.org/wiki/Lambert_W_function.

[63] Roels S, Carmeliet J, Hens H, Adan O, Brocken H, Cerny R, Pavlik Z, Hall C, Kumaran K, Pel L. Interlaboratory comparison of hygric properties of porous building materials. Journal of Building Physics. 2004;27:307-25. 
Postprint: Feng C, Janssen H. 2018. Hygric properties of porous building materials (III): impact factors and data processing methods of the capillary absorption test , Building and Environment, 134: 21-34.

doi: https://doi.org/10.1016/j.buildenv.2018.02.038

\section{Appendix 1 A model for analyzing regular and irregular $1^{\text {st }}$ stages}

In this appendix, we suggest a simplified permeability model for analyzing regular and irregular $1^{\text {st }}$ stages in the capillary absorption process, as illustrated in Fig.A1-1.

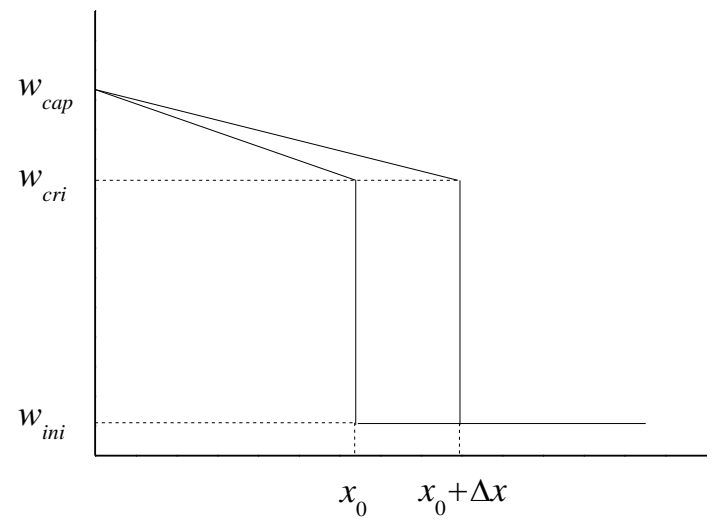

Fig.A1-1 The simplified 1-D capillary absorption model

Assuming a sample with a bottom surface area $A$ and an initial moisture content $w_{\text {ini }}\left(\mathrm{kg} \cdot \mathrm{m}^{-3}\right)$ is used for the 1-D capillary absorption. At time $t_{0}(\mathrm{~s})$ the water front is at position $x_{0}(\mathrm{~m})$. The moisture content at the sample bottom and the water front are capillary moisture content $w_{c a p}$ and critical moisture content $w_{c r i}\left(\mathrm{~kg} \cdot \mathrm{m}^{-3}\right)$, respectively (critical moisture content refers to the moisture content at which the liquid phase in a porous material forms continuity and thus dominates moisture transfer). Between the sample bottom and the water front both the moisture content and the capillary pressure $\left(p_{c}, \mathrm{~Pa}\right)$ distribution are assumed linear. The moisture flux $\dot{g}\left(\mathrm{~kg} \cdot \mathrm{m}^{-2} \mathrm{~s}^{-1}\right)$ can thus be expressed as:

$$
\dot{g}=-K_{c r i} \cdot \frac{\partial p_{c}}{\partial x}=-K_{c r i} \cdot \frac{p_{c, c r i}-p_{c, c a p}}{x_{0}}=-\frac{K_{c r i} \cdot p_{c, c r i}}{x_{0}}
$$

where $K_{c r i}$ is the moisture permeability at $w_{c r i}, \mathrm{~kg} \cdot \mathrm{m}^{-1} \mathrm{~s}^{-1} \mathrm{~Pa}^{-1}, p_{c, c r i}$ and $p_{c, \text { cap }}$ the capillary pressure at $w_{c r i}$ and $w_{c a p}$, respectively, Pa. $p_{c, c a p}$ is assumed to be 0 .

After a time interval of $\Delta t$, the water front moves to $x_{0}+\Delta x$. Within this period of time, the increased moisture $\Delta m_{\text {wet }}$ amounts to:

$$
\Delta m_{w e t}=\dot{g} \cdot \Delta t \cdot A=-\frac{K_{c r i} \cdot p_{c, c r i}}{x_{0}} \cdot \Delta t \cdot A
$$

The increased moisture can also be calculated based on the area increase shown in Fig.A1-1:

$$
\Delta m_{w e t}=\left[\left(w_{c r i}-w_{i n i}\right) \cdot \Delta x+\frac{1}{2}\left(w_{c a p}-w_{c r i}\right) \cdot \Delta x\right] \cdot A=\left(\frac{w_{c a p}+w_{c r i}}{2}-w_{i n i}\right) \cdot \Delta x \cdot A=\Delta w \cdot \Delta x \cdot A
$$

where $\Delta w\left(\mathrm{~kg} \cdot \mathrm{m}^{-3}\right)$ is defined as:

$$
\Delta w=\frac{w_{c a p}+w_{c r i}}{2}-w_{i n i}
$$

Eq.( A1-2) and Eq.( A1-3) can be put together and rewrite into a differential equation:

$$
\frac{\partial x}{\partial t}=\frac{-K_{c r i} \cdot p_{c, c r i}}{\Delta w \cdot x}
$$

By solving Eq.( A1-5) we obtain:

$$
\frac{\Delta m_{w e t}(t)}{A}=\sqrt{-2 K_{c r i} \cdot p_{c, c r i} \cdot \Delta w} \cdot \sqrt{t}=A_{c a p} \cdot \sqrt{t}
$$


Postprint: Feng C, Janssen H. 2018. Hygric properties of porous building materials (III): impact factors and data processing methods of the capillary absorption test , Building and Environment, 134: 21-34.

doi: https://doi.org/10.1016/j.buildenv.2018.02.038

The capillary absorption coefficient $A_{c a p}$ is hence defined, and the square root of time behavior is also confirmed.

The above analysis doesn't take gravity into account. If we consider gravity as the main reason for the irregular $1^{\text {st }}$ stage behavior, we can integrate the gravity term into Eq.(A1-5) and get:

$$
\frac{\partial x}{\partial t}=\frac{-K_{c r i} \cdot\left(p_{c, c r i}+\rho_{w} \cdot g \cdot x\right)}{\Delta w \cdot x}
$$

where $\rho_{w}$ is water density $\left(\mathrm{kg} \cdot \mathrm{m}^{-3}\right)$ and $g$ is the gravitational acceleration $\left(\mathrm{m} \cdot \mathrm{s}^{-2}\right)$.

Eq.(A1-7) can be rewritten as:

$$
\frac{\partial x}{\partial t}=-\frac{K_{c r i} \cdot p_{c, c r i}}{\Delta w \cdot x}-\frac{K_{c r i} \cdot \rho_{w} \cdot g}{\Delta w}=-\frac{a}{x}-b
$$

where $a$ and $b$ are short for:

$$
a=\frac{K_{c r i} \cdot p_{c, c r i}}{\Delta w \cdot x}<0, b=\frac{K_{c r i} \cdot \rho_{w} \cdot g}{\Delta w}>0
$$

With the initial condition $x(0)=0$, the solution to Eq. (A1-8) is:

$$
x(t)=-\frac{a}{b}\left[W\left(-e^{\frac{b^{2}}{a} \cdot t-1}\right)+1\right]
$$

where $W$ is the Lambert $W$-function.

The Lambert $W$-function is a multi-valued complex function. In our case time $t$ and the corresponding water front distance $x(t)$ are always positive except for $x(0)=0$. Thus we are looking at the single- and real-valued part of the function $W_{0}$ :

$$
x(t)=-\frac{a}{b}\left[W_{0}\left(-e^{\frac{b^{2}}{a} \cdot t-1}\right)+1\right]
$$

Simple calculations reveal that:

$$
\begin{gathered}
x(0)=-\frac{a}{b}\left[W_{0}\left(-e^{\frac{b^{2}}{a} \cdot 0-1}\right)+1\right]=-\frac{a}{b}\left[W_{0}\left(-\frac{1}{e}\right)+1\right]=0 \\
x(\infty)=-\frac{a}{b}\left[W_{0}\left(-e^{\frac{b^{2}}{a} \cdot \infty-1}\right)+1\right]=-\frac{a}{b}\left[W_{0}\left(-\frac{1}{e^{\infty}}\right)+1\right]=-\frac{a}{b}=-\frac{p_{c, c r i}}{\rho_{w} \cdot g}
\end{gathered}
$$

Eq.(A1-12) and Eq.(A1-13) are both mathematically and physically reasonable. Eq.(A1-11) is therefore validated.

In practice, it is the sample's dry and wet mass $\left(m_{d r y}\right.$ and $\left.m_{w e t}, \mathrm{~kg}\right)$ rather than the water front distance that is measured directly. Thus we transform Eq.(A1-11) into Eq.(A1-14), whose left side is the frequently used cumulative inflow:

$$
\frac{m_{w e t}(t)-m_{d r y}}{A}=-\Delta w \cdot \frac{a}{b}\left[W_{0}\left(-e^{\frac{b^{2}}{a} \cdot t-1}\right)+1\right]
$$

For physical interpretation we can simply take Eq.(A1-4) and Eq.(A1-9) into Eq.(A1-14) to obtain the following equation: 


$$
\frac{m_{w e t}(t)-m_{d r y}}{A}=-\frac{p_{c, c r i}}{\rho_{w} \cdot g}\left(\frac{w_{c a p}+w_{c r i}}{2}-w_{i n i}\right)\left[W _ { 0 } \left(-e^{\frac{K_{c r i} \cdot \rho_{w}^{2} \cdot g^{2}}{p_{c, r i} \cdot\left(\frac{w_{c a p}+w_{c r i}}{2}-w_{i n i}\right)}} \cdot t-1\right.\right.
$$

where all parameters have clear physical meanings.

For mathematical simplicity Eq.(A1-14) is preferred. To account for the non-zero intercept, we add another fitting parameter $k$ and obtain:

$$
\frac{m_{w e t}(t)-m_{d r y}}{A}=-\Delta w \cdot \frac{a}{b}\left[W_{0}\left(-e^{\frac{b^{2}}{a} \cdot t-1}\right)+1\right]+k
$$

The parameters $\Delta w, a, b$ and $k$ should be adjusted so that the fitted curve (the cumulative inflow) is the closest to the measurements using the least square method. The Lambert $W_{0}$-function is transcendental and can not be calculated directly. The Newton's iteration is an optional method for its estimation:

$$
W_{0}(z)_{i+1}=W_{0}(z)_{i}-\frac{W_{0}(z)_{i} \cdot e^{W_{0}(z)_{i}}-z}{e^{W(z)_{i}}\left[W_{0}(z)_{i}+1\right]}
$$

where in our case $z=-e^{\frac{b^{2}}{a} \cdot t-1}<0$.

Since the lower limit of the Lambert $W_{0}$-function is $-1 / \mathrm{e}$, the domain of the Lambert $W_{0}$-function in our study becomes $(-1 / \mathrm{e}, 0)$. Within this domain, we adopt the following approximation:

$$
W_{0}(z) \approx 1.57992 \cdot(z+0.36845)^{0.3403}-1.12222
$$

Fig.A1-2 Approximation of the Lambert $W_{0}$-function in (-1/e, 0$)$

Also note that:

$$
A_{c a p}=\Delta w \sqrt{-2 a}
$$

We finally rewrite Eq.(A1-16) into the following analytical function for direct fitting:

$$
\frac{m_{w e t}(t)-m_{d r y}}{A}=A_{c a p} \cdot k_{1} \cdot\left(0.5103-1.3849 \cdot e^{-\frac{t}{k_{1}^{2}-1}}\right)^{0.3403}+k_{2}
$$

where $A_{\text {cap }}$ is the desired capillary absorption coefficient, while $k_{1}$ and $k_{2}$ are fitting parameters. 
Postprint: Feng C, Janssen H. 2018. Hygric properties of porous building materials (III): impact factors and data processing methods of the capillary absorption test , Building and Environment, 134: 21-34.

doi: https://doi.org/10.1016/j.buildenv.2018.02.038

\section{Appendix 2 Analysis of taking the arithmetic mean value of $\mathrm{d}\left[\left(m_{\text {wet }}-m_{\text {dry }}\right) / A\right] / \mathrm{d} t^{0.5}$ as $A_{\text {cap }}$}

Here we just consider the $1^{\text {st }}$ stage of the capillary absorption process.

Assuming that at time $t_{i}$ the wet mass of the sample (dry mass $m_{d r y}$, bottom surface area $A$ ) is $m_{\text {wet }}\left(t_{i}\right)$, then by performing backward difference (for forward or central difference, the conclusion still stands) Eq.(A2-1) can be obtained:

$$
s_{i}=\frac{d\left[\left(m_{w e t}-m_{d r y}\right) / A\right]}{d t^{0.5}} \approx \frac{\left[m_{w e t}\left(t_{i}\right)-m_{d r y}\right]-\left[m_{w e t}\left(t_{i-1}\right)-m_{d r y}\right]}{A \cdot\left(t_{i}^{0.5}-t_{i-1}^{0.5}\right)}=\frac{m_{w e t}\left(t_{i}\right)-m_{w e t}\left(t_{i-1}\right)}{A \cdot\left(t_{i}^{0.5}-t_{i-1}^{0.5}\right)}
$$

where $s_{i}\left(\mathrm{~kg} \cdot \mathrm{m}^{-2} \mathrm{~s}^{-0.5}\right)$ is the slope, ideally equating to the capillary absorption coefficient $A_{c a p}$.

In reality, the arithmetic mean value can be used for approximation:

$$
A_{\text {cap }} \approx \frac{1}{n} \sum_{i=1}^{n} s_{i}=\frac{1}{n \cdot A} \sum_{i=1}^{n} \frac{m_{w e t}\left(t_{i}\right)-m_{w e t}\left(t_{i-1}\right)}{t_{i}^{0.5}-t_{i-1}^{0.5}}
$$

Now we check the case $n=2$ :

$$
A_{\text {cap }} \approx \frac{1}{2 A} \cdot\left[\frac{m_{\text {wet }}\left(t_{2}\right)-m_{\text {wet }}\left(t_{1}\right)}{t_{2}^{0.5}-t_{1}^{0.5}}+\frac{m_{w e t}\left(t_{1}\right)-m_{\text {wet }}\left(t_{0}\right)}{t_{1}^{0.5}-t_{0}^{0.5}}\right]
$$

If the differences between the square root of time are the same, as expressed by:

$$
\Delta t^{0.5}=t_{2}^{0.5}-t_{1}^{0.5}=t_{1}^{0.5}-t_{0}^{0.5}
$$

Then Eq.(A2-3) can be simplified to:

$$
A_{\text {cap }} \approx \frac{1}{2 A} \cdot \frac{m_{w e t}\left(t_{2}\right)-m_{w e t}\left(t_{0}\right)}{\Delta t^{0.5}}
$$

where the contribution of the measurement at $t_{1}$ disappears. This indicates that if $\Delta t^{0.5}$ remains the same for adjacent measurements, then the information of some measurements is useless.

For real situations $\Delta t^{0.5}$ doesn't remain unchanged. However, whenever successive $\Delta t^{0.5}$ are similar, the importance of some measurements becomes less. On the contrary, this is not the case for linear fittings, where all points make equal contributions.

To conclude, taking the arithmetic mean value of $\mathrm{d}\left[\left(m_{w e t}-m_{d r y}\right) / A\right] / \mathrm{d} t^{0.5}$ as $A_{\text {cap }}$ is mathematically inferior to the linear fitting used in the traditional one-tangent method. 
Postprint: Feng C, Janssen H. 2018. Hygric properties of porous building materials (III): impact factors and data processing methods of the capillary absorption test, Building and Environment, 134: 21-34.

doi: https://doi.org/10.1016/j.buildenv.2018.02.038

Nomenclature

\begin{tabular}{|c|c|c|}
\hline Symbol & Unit & Meaning \\
\hline$A$ & $\mathrm{~m}^{2}$ & Bottom surface area \\
\hline$A_{\text {cap }}$ & $\mathrm{kg} \cdot \mathrm{m}^{-2} \mathrm{~s}^{-0.5}$ & Capillary absorption coefficient \\
\hline$a$ & $\mathrm{~m} \cdot \mathrm{s}^{-1}$ & $a=\left(K_{c r i} \cdot p_{c, c r i}\right) /(\Delta w \cdot x)$ \\
\hline$b$ & $\mathrm{~m} \cdot \mathrm{s}^{-1}$ & $b=\left(K_{c r i} \cdot \rho_{w} \cdot g\right) / \Delta w$ \\
\hline$g$ & $\mathrm{~m} \cdot \mathrm{s}^{-2}$ & Gravitational acceleration \\
\hline$\dot{g}$ & $\mathrm{~kg} \cdot \mathrm{m}^{-2} \mathrm{~s}^{-1}$ & Moisture flux \\
\hline$H$ & $\mathrm{~m}$ & Height \\
\hline$K_{c r i}$ & $\mathrm{~kg} \cdot \mathrm{m}^{-1} \mathrm{~s}^{-1} \mathrm{~Pa}^{-1}$ & Moisture permeability at $w_{c r i}$ \\
\hline$k, k_{1}, k_{2} \ldots$ & - & Fitting parameters \\
\hline$m_{d r y}$ & $\mathrm{~kg}$ & Dry mass \\
\hline$m_{w e t}$ & $\mathrm{~kg}$ & Wet mass \\
\hline$p_{c}$ & $\mathrm{~Pa}$ & Capillary pressure \\
\hline$p_{c, c r i}$ & $\mathrm{~Pa}$ & Capillary pressure at $w_{c r i}$ \\
\hline$p_{c, c a p}$ & $\mathrm{~Pa}$ & Capillary pressure at $w_{c a p}$ \\
\hline$R^{2}$ & - & Coefficient of determination \\
\hline$R_{50}$ & $\mathrm{~m}$ & Median pore-throat radius \\
\hline$S$ & $\mathrm{~m} \cdot \mathrm{s}^{-0.5}$ & Sorptivity \\
\hline$s_{i}$ & $\mathrm{~kg} \cdot \mathrm{m}^{-2} \mathrm{~s}^{-0.5}$ & The slope at time $t_{i}$ in the $1^{\text {st }}$ stage \\
\hline$T$ & $\mathrm{~K}$ & Temperature \\
\hline$t$ & $\mathrm{~s}$ & Time \\
\hline$t_{0}$ & $\mathrm{~s}$ & Starting time \\
\hline$t_{\text {end }}$ & $\mathrm{s}$ & Ending time \\
\hline$u_{84.7 \%}$ & $\mathrm{~kg} \cdot \mathrm{kg}^{-1}$ & Equilibrium moisture content at RH $84.7 \%$ \\
\hline$W$ & - & Lambert $W$-function. \\
\hline$W_{0}$ & - & The single- and real-valued part of $W$ \\
\hline$w_{\text {cap }}$ & $\mathrm{kg} \cdot \mathrm{m}^{-3}$ & Capillary moisture content \\
\hline$w_{c r i}$ & $\mathrm{~kg} \cdot \mathrm{m}^{-3}$ & Critical moisture content \\
\hline$w_{\text {ini }}$ & $\mathrm{kg} \cdot \mathrm{m}^{-3}$ & Initial moisture content \\
\hline$\Delta w$ & $\mathrm{~kg} \cdot \mathrm{m}^{-3}$ & $\Delta w=\left(w_{c a p}+w_{c r i}\right) / 2-w_{i n i}$ \\
\hline$x$ & $\mathrm{~m}$ & Position \\
\hline$x_{0}$ & $\mathrm{~m}$ & Initial position at $t_{0}$ \\
\hline$x_{\text {cross }}$ & $\mathrm{s}^{0.5}$ & $\mathrm{x}$-coordinate of the cross point of the $1^{\text {st }}$ and $2^{\text {nd }}$ stages \\
\hline$y_{\text {cross }}$ & $\mathrm{kg} \cdot \mathrm{m}^{-2}$ & $y$-coordinate of the cross point of the $1^{\text {st }}$ and $2^{\text {nd }}$ stages \\
\hline & - & $z=-\exp \left(t \cdot b^{2} / a-1\right)$ \\
\hline \multicolumn{3}{|l|}{ Greek letters } \\
\hline$\gamma_{w}$ & $\mathrm{~N} \cdot \mathrm{m}^{-1}$ & Surface tension of water \\
\hline$\mu$ & - & Vapor diffusion resistance factor \\
\hline$\mu_{w}$ & $\mathrm{~Pa} \cdot \mathrm{s}$ & Viscosity of water \\
\hline$\rho_{\text {bulk }}$ & $\mathrm{kg} \cdot \mathrm{m}^{-3}$ & Bulk density \\
\hline$\rho_{w}$ & $\mathrm{~kg} \cdot \mathrm{m}^{-3}$ & Water density \\
\hline$\phi$ & - & Open porosity \\
\hline
\end{tabular}

